FEDERAL RESERVE BANK OF SAN FRANCISCO

WORKING PAPER SERIES

\title{
The Effect of an Employer Health Insurance Mandate on Health Insurance Coverage and the Demand for Labor: Evidence from Hawaii
}

\author{
Thomas C. Buchmueller \\ University of Michigan \\ John DiNardo \\ University of Michigan \\ Robert G. Valletta \\ Federal Reserve Bank of San Francisco
}

\begin{abstract}
April 2011
Working Paper 2009-08

http://www.frbsf.org/publications/economics/papers/2009/wp09-08bk.pdf
\end{abstract}

The views in this paper are solely the responsibility of the authors and should not be interpreted as reflecting the views of the Federal Reserve Bank of San Francisco or the Board of Governors of the Federal Reserve System. 


\title{
The Effect of an Employer Health Insurance Mandate on Health Insurance Coverage and the Demand for Labor: Evidence from Hawaii
}

\author{
Thomas C. Buchmueller \\ Stephen M. Ross School of Business \\ University of Michigan \\ 701 Tappan Street \\ Ann Arbor, MI 48109 \\ Email: tbuch@umich.edu \\ John DiNardo \\ Gerald R. Ford School of Public Policy \\ and Department of Economics \\ University of Michigan \\ 735 S. State St. \\ Ann Arbor, MI 48109 \\ Email: jdinardo@umich.edu \\ Robert G. Valletta \\ Federal Reserve Bank of San Francisco \\ 101 Market Street \\ San Francisco, CA 94105 \\ email: rob.valletta@sf.frb.org
}

April 2011

JEL Codes: J32, I18, J23

Keywords: health insurance, employment, hours, wages

The authors thank Meryl Motika, Jaclyn Hodges, Monica Deza, Abigail Urtz, Aisling Cleary, and Katherine Kuang for excellent research assistance, Jennifer Diesman of HMSA for providing data, and Gary Hamada, Tom Paul, and Jerry Russo for providing essential background on the PHCA. Thanks also go to Nate Anderson, Julia Lane, Reagan Baughman, and seminar participants at Michigan State University, the University of Hawaii, Cornell University, and the University of Illinois (Chicago and Urbana-Champaign) for helpful comments and suggestions on earlier versions of the manuscript. The views expressed in this paper are those of the authors and should not be attributed to the Federal Reserve Bank of San Francisco or the Federal Reserve System. 


\title{
The Effect of an Employer Health Insurance Mandate on Health Insurance Coverage and the Demand for Labor: Evidence from Hawaii
}

\begin{abstract}
We examine the effects of the most durable employer health insurance mandate in the United States, Hawaii's Prepaid Health Care Act, using Current Population Survey data covering the years 1979 to 2005. We find that Hawaii's law increased insurance coverage over time for worker groups with low rates of coverage in the voluntary market. We find no statistically significant support for the hypothesis that the mandate reduced wages and employment probabilities. Instead, its primary detectable effect was an increased reliance on part-time workers who are exempt from the law. We arrive at these conclusions in part by use of a variation of the classical Fisher permutation test that compares the magnitude of the estimated "Hawaii effect" to "placebo effects" estimated for the other US states.
\end{abstract}




\section{The Effect of an Employer Health Insurance Mandate on Health Insurance Coverage and the Demand for Labor: Evidence from Hawaii}

\section{INTRODUCTION}

Long before passage of the federal health care reform act in 2010, which eventually will impose an individual mandate to obtain health insurance, policy makers had considered the alternative approach of employer health insurance mandates as a strategy for expanding coverage. At the Federal level, the failed health care reform plans proposed by the Nixon administration in the early 1970s and the Clinton administration twenty years later both included an employer mandate. At the state level, laws imposing employer mandates in Massachusetts (1988), Oregon (1989), Washington (1993), and California (2003) were overturned by voter referendums or voided due to conflicts with the federal Employee Retirement Insurance Security Act (ERISA). Since these laws have not been adopted, direct evidence regarding the effects of an employer sponsored insurance (ESI) mandate is scarce. One state law that has been enforced for over two decades and therefore provides a potential source of information on ESI mandates is Hawaii’s Prepaid Health Care Act (PHCA). Hawaii’s mandate requires that essentially all private sector employers provide health insurance coverage to employees working at least 20 hours per week on a regular basis.

Despite the significance of Hawaii's law and its relevance to ongoing policy debates, quantitative research on its effects is limited (Dick 1994, Thurston 1997, Lee et al. 2005). A key reason for the paucity of research is timing: the PHCA legislation was passed in 1974, five years before any national survey provided information on health insurance coverage for individuals, making it difficult to compare outcomes before and after the passage of the law. While the early passage of the PHCA creates significant research hurdles, it does not preclude a meaningful 
analysis of the law's impact. As we show later, because ESI coverage was relatively stable in Hawaii while it declined in other states over the past few decades, the coverage gap between Hawaii and other states widened over time, particularly for worker groups with low rates of ESI coverage. This divergence in coverage, combined with substantial growth in the relative price of health care over the same period, implies that the cost of complying with the mandate has grown over time. As a result, data pre-dating the original PHCA legislation is not necessary for testing the hypothesis that the mandate has had labor market effects.

In this paper we use Current Population Survey (CPS) data for the years 1979 to 2005 to compare trends in health insurance coverage and three labor market outcomes-wages, hours, and employment—between Hawaii and the rest of the United States. Compared with previous work, our analysis is the first to account for the prediction that the effects of Hawaii's mandate should be strongest for workers who are unlikely to receive health benefits in a voluntary market - primarily low-skill workers — and should be minimal for workers with high rates of ESI coverage in the absence of a mandate. Ours is also the first study to analyze the complete range of predicted outcomes in a "difference-in-differences" setting: we use repeated cross-sections from the CPS to compare changes over time in ESI coverage, alternative sources of coverage, and labor market outcomes between Hawaii and the rest of the nation, conditional on an extensive set of control variables.

Given the likely influence of unobserved effects at the state level, we take a conservative approach to statistical inference by relying on a variant of Fisher's (1935) permutation test. Our tests entail comparisons of the usual difference in conditional means between the United States and Hawaii to parallel "placebo" comparisons between each of the other 50 states (plus DC) and the remainder of the United States. We find that by this metric Hawaii has an unusually high 
fraction of individuals with ESI coverage compared with other states, and this gap has grown over time for groups with low coverage rates, consistent with the expected effects of the mandate. Using the same framework, we find that the increase in ESI coverage was mirrored by a similar decline in insurance coverage through public sources (e.g., Medicaid). We also uncover a rising tendency for Hawaiian employers to rely on part-time positions that are exempt from the law. Like the coverage results, the effects on part-time work are concentrated on workers with low probabilities of receiving health benefits in the absence of an employer mandate. By contrast, we find that Hawaii's distribution of wages and employment has not diverged significantly from that in other states.

\section{BACKGROUND AND PREVIOUS LITERATURE}

\section{II.A. Hawaii's Health Insurance Mandate}

Hawaii's employer mandate legislation (PHCA) was passed in 1974, the same year that the U.S. Congress passed ERISA, which established Federal regulation of employer-sponsored benefit programs. ERISA preempts state laws and has been interpreted by the courts as prohibiting state laws mandating that employers provide health insurance benefits (Mariner 1992). Shortly after it took effect in January of 1975, the PHCA was successfully challenged on ERISA grounds; this decision was upheld by the U.S. Court of Appeals in 1980 and by the U.S. Supreme Court in 1981. In 1983, the U.S. Congress granted a permanent ERISA exemption to PHCA. Because that legislation specified that substantive changes to PHCA would void the exemption, the law has been largely unchanged since then (Oliver 2004).

The PHCA requires all private-sector employers in Hawaii to provide health insurance to employees working 20 or more hours per week. Non-complying employers face financial 
sanctions and can be shut down after 30 days. In addition to low-hours employees, exemptions also apply to new hires (employed less than four weeks), seasonal employees, commission-only workers, and "low-wage" employees. ${ }^{1}$ Employers must pay at least $50 \%$ of the premium cost, and the employee contribution is limited to an amount that is no greater than $1.5 \%$ of their wages. Qualifying health insurance plans are required to contain certain minimal benefits, including inpatient hospital coverage, emergency room care, maternity care, and medical and surgical services.

Available evidence suggests that the legal uncertainty surrounding PHCA's status limited the law's impact between its 1975 enactment and the Federal intervention in 1983. One estimate is that after the law went into effect, private insurance enrollment increased by no more than 5,000 individuals, slightly less than one percent of the state's working-age population (Friedman 1993, p. 54). ${ }^{2}$ Moreover, the state suspended employer compliance audits between the first court ruling in 1977 and exhaustion of the state's judicial appeals in 1981 (Agsalud 1982, p. 14). On the other hand, as we show in Section IV, conditional on observable factors, ESI coverage was already higher in Hawaii than it was in most other states during this early period. This gap widened after 1983, which is important for our empirical framework.

\section{II.B. The Economics of Employer Mandated Health Insurance}

Summers (1989) showed how the labor market effects of an employer benefit mandate can be analyzed using a simple supply and demand framework. In his analysis, a mandate causes the labor demand curve to shift back and the labor supply curve to shift out, causing wages to fall. The magnitude of the wage change, and the effect on hours and employment, will depend

\footnotetext{
${ }^{1}$ Low-wage workers are defined as those with monthly earnings less than 86.67 times the legislated minimum hourly wage.

${ }^{2}$ The U.S. GAO (1994, p. 16) also noted limited enrollment increases after the mandate took effect.
} 
on how workers' valuation of the benefit compares with employers' cost of provision.

In the absence of any pre-existing market failures, the benefit will be voluntarily provided to workers whose valuation exceeds employers' cost. Therefore, such workers should not be directly affected by a mandate. Instead, the most important effects of a mandate will be on workers who would not otherwise receive the benefit, either because their valuation falls short of its cost or because their wage is close to the minimum wage and therefore cannot be reduced enough to offset the cost of the benefit. Thus, the effects of the mandate on ESI coverage should be largest for low-wage, low-skill workers, who generally exhibit low rates of coverage in a voluntary market. Some of this increase in coverage may be offset by declines in coverage provided to working spouses. ${ }^{3}$ In addition, increases in ESI coverage among low-wage workers may offset coverage through public sources such as Medicaid.

For workers most affected by the mandate, whose valuation of ESI falls short of its cost, the wage reduction arising from the market adjustment to the mandate will fall short of the cost of the benefit. Employers will therefore face incentives to substitute exempt for covered workers. If this type of adjustment is not sufficient to offset the remaining costs of the mandate, relative labor costs rise for covered workers and employers may act to reduce employment of these workers. We test for such effects in our empirical section, focusing on worker groups whose ESI coverage rates rose by the largest amount in response to the mandate.

\section{II.C. Past Research on Hawaii's Mandate}

Any analysis of the PHCA must begin by estimating the law's effect on insurance coverage. Several prior studies used cross-sectional data to compare insurance coverage in

\footnotetext{
${ }^{3}$ The PHCA requires employers to cover a large share of the premiums for employees but imposes weaker requirements regarding contributions for dependent coverage. As a result, the out-of-pocket cost to employees of adding dependents is not necessarily lower in Hawaii than in other states, and married workers may face incentives to receive own ESI coverage rather than coverage as a dependent.
} 
Hawaii and the rest of the nation, with mixed results. Based on a cross-section analysis of Current Population Survey (CPS) data from the mid-1980s, Dick (1994) concluded that the PHCA did not raise insurance coverage rates in Hawaii relative to other states. However, the other studies, which used CPS data from later years in a cross-sectional framework, found that ESI coverage was significantly higher in Hawaii and attributed this result to the PHCA (Thurston 1997, Lee et al. 2005). Differences in data and research design make it difficult to reconcile these divergent results. ${ }^{4}$

To the extent that the PHCA prevented employers in Hawaii from dropping coverage in response to rising premiums, as was observed for the nation as a whole over the past few decades, we should expect to see adjustments along other margins, such as wages, hours, or employment. The existing literature provides limited evidence on these labor market effects. Thurston (1997) investigated the wage effects of Hawaii's mandate using data from the 1970 and 1990 Censuses aggregated to the industry level (with ESI coverage measured in 1990 only). He found mixed evidence for wage reductions due to the expansion of ESI, with results that are highly sensitive to assumptions regarding counterfactual wage trends.

Thurston also tested for an effect on part-time work, again using aggregated industry data from the 1970 and 1990 Censuses. His comparisons across industries based on ESI coverage in 1990 provided weak evidence in favor of the claim that the percentage of workers with low hours increased more in Hawaii than in the rest of the United States. In addition to the inability to identify changes in ESI coverage over time, a further limitation of his analysis is that the measures of "low hours" work consistently available in his data used weekly hours cut-offs of 15

\footnotetext{
${ }^{4}$ Relying on anecdotal evidence, some analysts have argued that the passage of PHCA had little immediate effect, but once the law was in place it slowed the erosion of employment based coverage as health care costs rose, leading to growing differences between Hawaii and other states over time (Neubauer 1993; U.S. GAO 1994). Our results discussed in subsequent sections are consistent with this.
} 
and 30 hours, which are different than the 20 hour cut-off that defines coverage by the PHCA.

Lee et al.'s cross-sectional analysis also provided suggestive evidence that employers in Hawaii are more likely to employ workers on low-hour schedules.

Much of the discussion and critique of employer mandates has centered on their potential negative effects on employment. Several papers argued that for workers near the minimum wage, an employer mandate will have effects similar to an increase in the minimum wage (Yelowitz 2003; Baicker and Levy 2007; Burkhauser and Simon 2007). However, neither these studies nor the prior studies on Hawaii's PHCA tested whether the law had such a disemployment effect. Compared with the analyses we conduct below, none of the existing studies of Hawaii's PHCA tested for the expected differential impacts of the mandate across worker groups or investigated changes over time arising from the rising costs of compliance.

\section{DATA AND DESCRIPTIVE EVIDENCE}

\section{A. Sample Construction}

Our main analyses rely on annual data from the CPS March and Monthly Outgoing Rotation Group (MORG) files. ${ }^{5}$ We constructed repeated cross-sections for years starting with the availability of health insurance questions in the March survey in 1980 and continuing through the mid-2000s (survey years 1980-2006, which correspond to the reference years of 1979-2005, the same as in our MORG files). Unless otherwise indicated we focus on workers age 18-64 who are employed in the private sector (excluding the self employed); we exclude government

\footnotetext{
${ }^{5}$ The March CPS provides information on ESI and other sources of health insurance coverage during the prior calendar year. For the analysis of labor market outcomes, we use the MORG files, which provide data on earnings and hours in their main job at the time of the survey. Compared with the March data, the MORG provides larger sample sizes and is not subject to the recall bias that may affect the retrospective data from the March survey.
} 
employees because Hawaii's PHCA law does not apply to them and their inclusion could bias the cross-state comparisons (with the exception of their use in falsification tests, as described below). In our analyses of wages and hours, we exclude observations with imputed values of those variables. Additional details regarding the characteristics of our data files, variable definitions, and treatment of imputed and top-coded data are provided in Appendix A. Mean values of population and job variables for Hawaii and the rest of the U.S. are shown in Appendix B, Table B1 (not for publication; will be made available online). ${ }^{6}$

\section{III.B. Rising Costs of the PHCA: ESI Premiums and Coverage}

In considering the possible labor market effects of the PHCA, it is important to recognize that the burden of the mandate increased over time as the growth in health insurance premiums outstripped growth in prices and wages more generally. While employers in the rest of the nation also experienced rising insurance costs, unlike Hawaiian employers, they can avoid the rising costs by dropping ESI coverage. ${ }^{7}$

Figure 1 provides a sense of how the cost of the PHCA to employers has grown. The graph plots real (\$2005) single coverage health insurance premiums in Hawaii expressed as an hourly cost for a full-time worker for the years 1974 to $2005 .{ }^{8}$ In 1974 , the monthly single

\footnotetext{
${ }^{6}$ Small differences are evident between Hawaii and other states. In regard to demographics, Hawaii's population is somewhat more educated on average than the population in other states, and it has a very high share of individuals whose race/ethnicity is Asian/Pacific Islander (subsumed in "Other" in the table, for consistency over our sample frame). Hawaii's population was much less urban than the national average early in our sample frame but more urban at the end. Regarding industry characteristics, manufacturing accounts for a smaller share of employment in Hawaii than the rest of the United States, though this difference has declined over time. The gap in manufacturing is largely offset by a higher percentage of Hawaiian employment in personal services (which includes hotels and tourism).

${ }^{7}$ An analysis by the U.S. GAO (1994) concluded that from 1975 to 1993 health spending grew by similar amounts in Hawaii and the rest of the country. However, data from the Medical Expenditure Panel SurveyInsurance Component (MEPS-IC) show that ESI premiums grew less rapidly in Hawaii than nationwide after 1996, for single and family coverage.

${ }^{8}$ The premium data are from the Hawaii Medical Service Association (HMSA), the largest private insurer in Hawaii, and they correspond to the most popular plan sold to groups of 100 or fewer.
} 
coverage premium for a plan meeting the standards of the PHCA was $\$ 15.96$, which for an employee working 40 hours per week (assuming 4.3 weeks per month) translated to a cost of 9 cents per hour in current dollars, or 36 cents in 2005 dollars. The cost per hour was only slightly higher in 1979, the first year in our data set, but then increased steadily thereafter. By 2005 the monthly premium was $\$ 246$, or $\$ 1.43$ per hour for a full-time employee, more than three times the real cost in 1980. The cumulative increase in the inflation-adjusted costs of insurance coverage over our sample frame ( $\$ 1.07$ per hour worked) dwarfs the cost of providing health insurance at the time the law was passed in 1975 (\$0.38 per hour) and when it was permanently authorized by the U.S. Congress in 1983 ( $\$ 0.60$ per hour). This implies that our strategy of examining cumulative changes over time is likely to dominate the alternative strategy based on before/after comparisons (which is not possible using available individual data in any event).

To complement the discussion of rising health insurance costs, we now turn to a descriptive comparison of trends in health insurance coverage in Hawaii and the rest of the United States. Figure 2 displays data on the percentage of private sector workers who received health insurance coverage through their own employer, for the years 1979 to 2005 . Panel A displays the series for all workers, with separate lines indicating the series for Hawaii, the remainder of the United States, and the difference between them. At the beginning of the sample frame the unadjusted coverage rate in Hawaii is about 4 percentage points above that in the rest of the country. Over time, the gap rises, as the coverage rate is largely maintained in Hawaii (at about $68 \%$ ) but falls elsewhere. At the end of the sample frame, the ESI coverage rate was about 14 percentage points higher in Hawaii (68\% vs. $54 \%$ for the years $2004-05){ }^{9}$

\footnotetext{
${ }^{9}$ It may seem surprising that the coverage rate in Hawaii is well below 100 percent, given that there are few exemptions to the PHCA. We investigated this issue by conducting supplemental tabulations using establishment level data on insurance offers from the MEPS-IC and worker level data on eligibility and
} 
As noted earlier, the basic supply and demand theory predicts that the effect of an employer mandate on health insurance coverage should be greatest for workers who have low rates of ESI coverage in the absence of a mandate, such as less skilled workers, and should have little effect on workers who have a high probability of receiving ESI in a voluntary market. A simple way to test this prediction is to divide the sample by educational attainment. Panels B and $\mathrm{C}$ of Figure 2 display own ESI coverage rates for workers with a high school degree or less and a college degree or more (workers with some college but no degree are excluded from these samples). The results are consistent with our expectations. The rising ESI coverage gap between Hawaii and the rest of the nation is largely confined to the low education sample. For that sample, the coverage gap between Hawaii and the rest of the country rose from about 3 percentage points in 1979-1980 to about 19 percentage points in 2004-05. By contrast, for college educated workers, Hawaii's ESI coverage gap shifted from positive to negative across different sub-periods, but it was around 3-4 percentage points at the start and periods of the sample frame, suggesting little impact of Hawaii's mandate for this group.

The combination of a large cumulative increase in ESI premium costs and a rising coverage gap between Hawaii and other states implies that the PHCA mandate has become increasingly costly to private-sector employers in Hawaii and therefore may have discernible labor market effects. Testing this proposition more formally requires a statistical conditioning framework, which we describe in the next section.

take-up from the CPS Contingent Worker Supplements; these data confirmed that most of this gap is accounted for by workers who decline coverage or are not eligible. 


\section{ECONOMETRIC STRATEGY}

\section{A. Permutation Tests}

The descriptive results discussed in the preceding section suggest that the ESI coverage gap between Hawaii and other states rose over our sample frame, particularly for low-skilled workers. We are interested in testing more formally whether ESI coverage increased over time in Hawaii relative to other states and also in testing for corresponding changes in labor market outcomes. We take a difference-in-differences approach that compares changes in ESI coverage and labor market outcomes in Hawaii to changes in the same outcomes in other states. Our estimates are derived from cross-sectional regressions run for the baseline period of 1979-1982 (when the legal status of Hawaii's PPHCA legislation was in dispute) and a later period. Since we are interested in the long run effects of the law, our analyses focus on the most recent set of years in our data extract (2002-2005) as the comparison period, though as a robustness test we experiment with other comparison periods. We estimate separate regressions for the two time periods rather than a single model with an interaction term, in order to allow for unrestricted effects of the covariates over time. Also, we pool multiple years in order to ensure adequate sample sizes for reliable estimation of the Hawaii effect. For each of the periods the model is:

$$
\mathrm{Y}_{i s t}=X_{i s t} \beta^{t}+Z_{s t} \gamma^{t}+H_{i t} \delta^{t}+\varphi_{s t}+\eta_{i t,} \quad(t=0,1)
$$

These equations are estimated using individual data from the CPS files. In addition to the time period indicator $t$ in equation (1), $i$ indexes individuals and $s$ indexes states. The dependent variables $Y$ that we analyze are: from the March CPS files, indicators of health insurance coverage (own-name ESI as well as alternative sources, as described below); and from the CPS 
MORG files, hourly wages, an indicator for working less than 20 hours per week (the hours cutoff determining PHCA coverage), and an indicator for employment. Equations for the indicator variables are estimated as logits, because some of the outcomes that we examine have means that are close to zero in our sample (e.g., low hours work and coverage through public insurance); for these equations, the key coefficients converted into percentage-point changes in the probability of the observed outcome (discussed in more detail in Section V.A). The equation for hourly wages is estimated as a log-linear regression.

For all outcomes we condition on individual $(X)$ and state-level $(Z)$ covariates; $\varphi_{s t}$ and $\eta_{i t}$ are an unobserved state effect and an i.i.d. disturbance, discussed in more detail below. ${ }^{10}$ Our focus is on the dummy variable $H$, which indicates whether an individual is living in Hawaii. The difference-in-differences estimate of the effect of Hawaii's PHCA law is given by the difference between the Hawaii effect in the comparison and baseline periods, or $\Delta=\delta^{l}-\delta^{0}$.

While estimation is straightforward in this setting, statistical inference is not. As Moulton (1990) demonstrates, assuming that the disturbances are i.i.d. (by ignoring the state effect $\varphi_{s t}$ ) leads to insufficiently conservative inference. In response to this concern, using the well-known "clustering" framework, inference relies on the asymptotic approximations

\footnotetext{
${ }^{10}$ The individual controls $(X)$ are education (5 categories), a quartic in age, gender, gender by age quartic interactions, married, married by gender interaction, race/ethnicity (4 categories), residence in an urban area, and veteran status. In the ESI, wage, and hours regressions (but not the alternative coverage and employment regressions) we control for industry and occupation (13 and 11 categories, respectively). The state-level variables $(Z)$ are annual measures of private sector union density, the state minimum wage, and the log change in the state Gross Domestic Product (GDP). Controlling for the minimum wage is important because its level is relatively high in Hawaii. State GDP is an important control because Hawaii's tourism-dependent economy is subject to shocks that can be independent of national economic conditions (e.g., a prolonged slump in the state caused by a sharp drop in Japanese tourism, which lasted for much of the 1990s). We include the state level union variable — obtained from Hirsch, MacPherson and Vroman (2001 and online) - because individual-level union membership is not available in the March CPS. Union membership is a strong predictor of ESI coverage (Buchmueller, DiNardo and Valletta 2002) and throughout our sample frame Hawaii's union density exceeds that of other states.
} 
associated with the assumption that the number of individuals within a state and/or the number of states grows large (Wooldridge 2006). This assumption does not apply in our setting, due to our focus on a single state. Moreover, some researchers have argued that inference is extremely problematic and perhaps impossible in such settings, because the comparison of a single state with all others collapses the degrees of freedom in the model and creates much larger sampling variance than is captured by the conventional asymptotic framework (Donald and Lang 2007). As noted by Wooldridge (2006), however, this argument is indistinguishable from the standard question of whether an observed conditional difference in measured outcomes is entirely due to the policy change of interest.

To address such concerns about our reliance on a single state as our experimental unit, we implement a variant of Fisher's (1935) permutation or randomization test. Our approach starts with estimation of equation (1) for both time periods using OLS. Instead of comparing this estimate of $\Delta$ to its asymptotic standard error obtained using conventional means, we compare our estimate to the 50 "placebo" estimates obtained by running 50 additional regressions for each time period and re-computing $\Delta$, in each case replacing $H$ with an indicator for one of the other 49 states or DC. The test statistic for the null hypothesis that the change for Hawaii is no different from the change for other states is formed by computing the percentile that $\Delta$ represents in the distribution of the placebo estimates. In other words, we treat the 50 placebo estimates as the sampling distribution for $\Delta .^{11}$ This yields p-values for the hypothesis that the treatment effect of Hawaii's PPHCA is different from zero. The resulting hypothesis tests are based on much

\footnotetext{
${ }^{11}$ For a more detailed discussion of this approach, see Imbens and Wooldridge (2009, section 4.2). For a recent application in a setting similar to ours (policy effects in a single state), see Abadie et al. (2009).
} 
more conservative and appropriate confidence intervals than those produced using the standard clustering alternative. ${ }^{12}$

\section{B. Accounting for Heterogeneous Policy Effects}

As noted earlier, the basic supply and demand theory predicts that the effect of an employer mandate on health insurance coverage should be greatest for workers who place a low value on health insurance and therefore have low rates of ESI coverage in the absence of a mandate, such as younger, less skilled workers, and should have little effect on workers who have a high probability of receiving ESI in a voluntary market. The results in Figure 2, which stratifies the data by education, are broadly consistent with this prediction. We can account for heterogeneous policy effects more precisely by using a full range of explanatory variables to categorize individuals according to their probability of receiving health benefits in a voluntary market. To do this we fit the following regression on the complete sample of observations excluding those in Hawaii, using a logit model estimated separately for each year of data:

$$
I_{i s t}=X_{i s t} \Gamma^{t}+Z_{s t} \Pi^{t}+\varepsilon_{i t}
$$

In (2), $I$ is an indicator variable for own-name ESI coverage, $X$ and $\mathrm{Z}$ are the same controls as in equation (1), and $i, s$, and $t$ index individuals, states, and year. Using the results of these regressions, we fit the probability of ESI coverage for each individual in the full sample (including Hawaii) and then sort the fitted probabilities and place individuals into quintiles of this distribution (separately for each year). While education plays an important role in this

\footnotetext{
${ }^{12}$ Our placebo estimates suggest important violations of the assumptions required for the usual clustered standard errors to be appropriate. For example, for some outcomes we investigate below, reliance on clustered standard errors would imply that virtually all of the placebo estimates are statistically significant at conventional levels.
} 
prediction equation, other variables are important predictors as well (see Appendix C, intended for the online version; it lists the results from the ESI equations discussed in the next section). ${ }^{13}$

\section{RESULTS: INSURANCE COVERAGE}

\section{V.A. Employer-Sponsored Insurance Coverage}

In Table 1 we list the regression-adjusted difference in own name ESI coverage between Hawaii and other states for the initial period $\left(\delta^{0}\right)$ in Panel A, the later period $\left(\delta^{1}\right)$ in Panel B, and the difference between these two estimates $(\Delta)$ in Panel C. For these numerical estimates and subsequent results from logit equations, the estimated Hawaii coefficient $\delta$ (and placebo coefficients) are converted into "Population Average Treatment Effects on the Treated" (PATT, using the terminology of Imbens and Wooldridge 2009), expressed in percentage terms. These represent the percentage-point change in the probability of the observed outcome arising from residence in Hawaii (or a placebo state), conditional on other covariates, using the state-specific distribution of covariates for the calculation. ${ }^{14}$

${ }^{13}$ This approach relates closely to that of Card (1996), who used predictions from a wage equation estimated for non-union workers to examine how the union wage effect varies by skill level. In the statistics literature, such an approach to characterizing "treatment effect heterogeneity" has been called a "prognostic score" (Hansen 2008).

${ }^{14}$ For example, the calculation of the PATT (in percentage-point terms) for a specific estimate of the Hawaii effect $\delta$ is:

$$
\operatorname{PATT}_{\delta}=\sum_{i \in(H=1)} \frac{1}{N_{H}}\left[\hat{G}_{i}(H=1)-\hat{G}_{i}(H=0)\right]
$$

The $\hat{G}^{\prime} s$ refer to the fitted logit probabilities (based on equation 1 ) for a specific individual $i$, with the coefficient on the Hawaii indicator included $(H=1)$ or excluded $(H=0)$. The PATT is the difference between these fitted probabilities averaged across the complete set of Hawaii observations used in the regression, with observations for other states excluded from the calculation; $N_{H}$ is the number of Hawaii observations. A similar procedure is followed to obtain the PATTs for the placebo estimates. Compared with the alternative calculation based on the entire sample in each case (the "PATE" in Imbens and Wooldridge 2009), the PATT relies on the state-specific covariate values $(i \in(H=1))$. 
For estimates of the Hawaii effect in Table 1, we list the $5^{\text {th }}$ and $95^{\text {th }}$ percentiles of the distribution of placebo estimates. In our framework, these values represent the lower and upper critical values for rejecting the null hypothesis that the Hawaii effect is zero, with the significance level of the two-sided test set to 10 percent. $^{15}$ Figure 3 provides a graphical illustration of the same results by showing Hawaii's position in the full distributions of placebo effects (plotted as histograms). Similar to Table 1, we report results for the two time periods as well as the estimated differences, once again separately identifying the Hawaii value (the solid line) and the 5th and 95th percentile critical values (dashed lines).

Regarding emphasis on the 10 percent level for the test, recall that the significance level is determined by the rank of the Hawaii effect in the distribution of placebo effects. With 50 placebo estimates (49 states plus DC), achieving 10 percent significance requires that the Hawaii effect be ranked second from the top or bottom of the placebo distribution, while 5 percent significance requires that the Hawaii effect be ranked at the top or bottom. ${ }^{16}$ Because our placebo framework yields conservative confidence bounds, we emphasize the 10 percent significance level in the displays rather than the more common 5 percent level. In the tables, we also identify estimates that are significant at the 5 percent level, using conventional labels; in the figures, estimates that achieve 5 percent significance are identified by their position outside the span of the placebo histogram.

Turning to the results, recall from Figure 2 that in the early years of our data the percentage of private sector workers with ESI coverage was only about 4 percentage points

\footnotetext{
${ }^{15}$ For comparison purposes and also completeness, Appendix C reports results for the complete set of coefficients for the 2002-05 sub-sample regression, with conventional clustered standard errors listed. ${ }^{16}$ More precisely, ranking in the second position from the top or bottom implies 8 percent significance, while top or bottom ranking implies 4 percent significance. We have rounded up to the more common 10 percent and 5 percent levels.
} 
higher in Hawaii compared with other states. When we adjust for covariates, the difference rises substantially, to about 14 percentage points for the full sample (top left of Table 1 and Figure 3). This indicates that the distribution of covariates in Hawaii was consistent with lower coverage rates than in other states. The conditional coverage gap had risen somewhat by the end of our sample frame (2002-2005), to about 18 percentage points.

The breakdown by quintiles in Table 1 and Figure 3 indicates that the Hawaii effect is particularly large for the lower quintiles, representing worker types with low coverage probabilities in a voluntary market; the difference between Hawaii and other states ranges up to 28 percentage points for the lowest quintile in 2002-05, which represents more than a doubling of coverage relative to baseline rates for this group in other states (around 20 percent). In both time periods, except for the fifth quintile, the Hawaii effect lies beyond or near the boundary of the placebo distribution, implying a high degree of statistical significance according to our placebo testing criterion. For the first four quintiles, Hawaii is ranked at the top in nearly every case, indicating that the "Hawaii effect" is significant at the 5 percent level.

The key results for our difference-in-differences tests are the change effects (estimates of $\Delta$ ) displayed in the third panel of Table 1 and third column of Figure 3. For worker types with low coverage rates, in the first two quintiles of predicted coverage, the Hawaii gap grew substantially between $1979-82$ and 2002-05. The increase ranged from 7 to 10 percentage points and was larger in the second quintile, representing a near doubling of the conditional coverage gap (from 13 to 23 percentage points). For each of these quintiles, the increase in the Hawaii effect is significant at the 10 percent level using our placebo criterion, and nearly significant at the 5 percent level. In particular, the Hawaii effect is ranked second among the distribution of placebo estimates, slightly behind Massachusetts in the first quintile and Delaware in the second. 
These large Hawaii effects in the first two quintiles contribute to an effect for the full sample (first row) that is ranked towards the top of the distribution; the increase for Hawaii is about 4.1 percentage points, which ranks sixth, about 1.75 percentage points below the two top-ranked states. In contrast, for the top three quintiles the change in the Hawaii effect is smaller in magnitude and lies towards the middle of the placebo distribution, implying that for higher skill workers there was no statistically significant change in the coverage gap between Hawaii and other states. Overall, these results are consistent with the theoretical prediction that the law should raise relative ESI coverage in Hawaii versus other states for worker types with low rates of ESI coverage in the voluntary market (i.e., the bottom ESI quintiles).

\section{V.B. Insurance Coverage from Other Sources}

Although own-name ESI coverage is the outcome that should be most directly affected by an employer mandate, these effects may be offset by indirect effects on other sources of coverage. We examine that possibility here. Figure 4 displays results from regressions that are similar to the own ESI runs from Figure 3, incorporating the two other insurance outcomes that are consistently available across our sample frame: coverage as a dependent through a family member's ESI plan and coverage through public sources. ${ }^{17}$ For brevity, we only display the estimates for changes over time. The first column presents results for ESI coverage through either source (own or dependent), and the subsequent two columns list results for dependent ESI and public insurance. ${ }^{18}$ Following the full sample results in the first row, subsequent rows

\footnotetext{
${ }^{17}$ Public insurance consists primarily of Medicare, Medicaid, and programs for military veterans. We exclude overlapping coverage from the definitions: individuals with own and dependent coverage are recorded as having own ESI only, and individuals are identified as having public coverage if that is their sole source of coverage. The data on alternative coverage sources are discussed further in Appendix A. ${ }^{18}$ According to our measures, across the years in our data about 15 to 17 percent of the sample have ESI as a dependent and about 6 to 8 percent have coverage through public insurance; the latter numbers are low
} 
displays results for quintiles that reflect fitted probabilities of own ESI coverage, formed in the same manner as for Figure 3.

The results displayed in Figure 4 are suggestive of declines in alternative coverage sources - primarily public coverage — that offset rising own ESI coverage in Hawaii. In the first quintile, the significant increase in the Hawaii effect on own ESI coverage (Figure 3, second row, final column) is partially offset by a small, statistically insignificant decline in ESI as a dependent (Figure 4, second column, second row), yielding a statistically insignificant 5.8 percentage-point increase in overall ESI coverage for this quintile in Hawaii (Figure 4, first column, second row). By contrast, for the second quintile, the increase in own ESI in Hawaii (Figure 3) is not offset by a decline in ESI as a dependent, and the 10.4 percentage-point increase in overall ESI coverage in Hawaii is significant at nearly the 5\% level. In general, the Hawaii effect on the change in dependent coverage (Figure 4, second column) is highly insignificant according to our placebo criterion, with the exception of an anomalous result for the fourth quintile, for which the Hawaii effect is negative and significant at the 10 percent level. ${ }^{19}$

The results in the third column of Figure 4 indicate that coverage through public sources declined in Hawaii relative to other states, primarily in the first two quintiles, offsetting the rise in own ESI coverage in those quintiles. The Hawaii effects are negative and significant at just below the 10 percent level in the first two quintiles (ranked third from the bottom of the placebo distribution, close behind the required second rank). In the first quintile, the decline in the Hawaii effect on public coverage is 7.1 percentage points, which is large relative to the average

relative to published figures because our sample of 18-64 year old workers excludes the groups most likely to receive public coverage (the elderly, children, and non-workers).

${ }^{19}$ Thurston (1997) found that dependent coverage was lower in Hawaii than in the nation, although his reliance on cross-section data (years 1990-93) for this analysis precludes inferring a causal link from the mandate. 
public coverage rate of about 33 percent in this quintile. It is essentially identical to the estimated increase in own ESI coverage for this quintile, implying that the increase in own ESI was exactly offset by a decline in public coverage.

Overall, the alternative coverage results in Figure 4 indicate that the rise in own ESI for the first two quintiles (from Figure 3 and Table 1) was largely offset by declines in ESI from public sources, possibly accompanied by some reductions in dependent coverage that may reduce the cost burden of the mandate. These results help to explain the divergence among prior studies. Dick's (1994) conclusion that the PHCA had a minimal impact on insurance coverage was based on analysis of health insurance from any source, whereas Thurston (1997) and Lee et al. (2005) focused on own-name ESI.

\section{V.C. Robustness and Falsification Tests}

In this section, we discuss the results of several alternative data cuts, which help assess the robustness of our ESI coverage results and also provide falsification tests. We describe the results briefly here; the displays are contained in Appendix B, which is not intended for publication but will appear in an expanded online version of the paper.

Our analysis has focused on the long-run effects of Hawaii's PPHCA legislation, through a comparison between the start and end periods of our data (1979-82 and 2002-05). To examine the sensitivity of our results to the specific periods chosen, Figure B1 provides an analysis of own ESI coverage parallel to that in Table 3, but with two alternative, intermediate time periods: 1979-82 vs. $1990-93$, and $1990-93$ vs. $2002-05$. For brevity, we only display the results for changes over time. The results largely confirm the significant Hawaii effect for the first and second quintiles from Figure 3, although the sub-period breakdown in Figure B1 shows that the 
increase was most pronounced during the second sub-period for the first quintile and the first sub-period for the second quintile.

In addition to health insurance benefits, we also examined conditional trends in pension benefits. Examination of pensions serves as a falsification test for the effects of the PHCA mandate. If the increase in ESI coverage was accompanied by an increase in pension coverage, this would suggest that rising ESI was due to unobserved factors affecting employment benefits in Hawaii in general, rather than a direct effect of the PHCA.

We conducted permutation tests analogous to the ESI tests for two separate pension variables, indicating whether a workers' employer offers a pension to any of its employees, and whether the individual worker is covered by a pension plan (see Appendix A for additional details regarding these variables). The results are displayed in Appendix B (Figure B2); as before, and for brevity, we only display the change estimates $(\Delta) .{ }^{20}$ These results show that based on our placebo criterion, there was no increase in relative pension offers or coverage in Hawaii over our sample frame: the Hawaii effect generally is small and near the middle of the placebo distribution, or negative in some cases. The absence of an increase in pension availability and coverage suggests that the increase in ESI coverage in Hawaii (Figure 3) was likely due to the mandate rather than unobserved effects that increased benefit receipt in general.

Our preceding analyses have focused on private-sector workers, excluding government employees because Hawaii's mandate does not apply to them. As such, testing for a Hawaii effect on the change in ESI coverage for government employees constitutes a additional

\footnotetext{
${ }^{20}$ For this analysis, we formed the quintile groupings based on the fitted probabilities of pension offers and coverage. Separate runs indicated that the results are indistinguishable from those reported here when the quintiles are instead formed using fitted probabilities of ESI coverage instead.
} 
falsification test of our finding that the law increased coverage: if the Hawaii effect is caused by the mandate, we should not find a similar Hawaii effect for government employees.

The results of this test for government employees are displayed in Appendix B (Figure B3). ${ }^{21}$ The figure is constructed analogously to Figure 3, with the two sub-periods and change results displayed in three columns. On average, the point estimates indicate that government employees in Hawaii have slightly higher coverage rates than do government employees elsewhere. However, the Hawaii effect in general is statistically insignificant according to our placebo criterion. Moreover, the only significant increase over time is found for the fifth quintile, due to a large negative Hawaii effect in the initial sample period. This finding appears to reflect random elements in the data and does not falsify our private-sector ESI results because the mandate is not expected to affect the upper quintiles of the predicted ESI coverage distribution. On balance, these results for government employees do not falsify the findings regarding rising ESI coverage for private-sector employees.

\section{RESULTS: LABOR MARKET OUTCOMES}

Figure 1 showed that Hawaiian employers' cost of providing health insurance rose significantly over our sample frame. In addition, the ESI results in Table 1 and Figure 3 showed that by comparison with other states, own coverage rose significantly in Hawaii for workers whose characteristics are consistent with low rates of coverage in an unconstrained labor market. Combined, these sets of results indicate that Hawaii's mandate created rising costs over time for employers who hire such workers. Figure 4 showed that some of these costs may have been

\footnotetext{
${ }^{21}$ The quintiles were formed as before but based on the probability of ESI coverage for government employees only; industry and occupation variables were excluded from the list of controls.
} 
offset by slight declines in coverage as an ESI dependent, particularly in the first ESI quintile, implying that the overall mandate costs may be small.

Assuming net positive costs of the mandate, our demand-supply framework from Section II.B highlights three likely labor market effects. First, to the extent that employers are able to pass the cost of the mandate on to workers, wage growth for affected workers should be lower in Hawaii than in other states. If the wage offset is incomplete, perhaps because of a binding minimum wage, the mandate may affect labor demand by raising the cost of employing less skilled workers. One potential response is that employers may increase their reliance on parttime workers who are exempt from the mandate. Alternatively, firms may hire fewer workers from the available labor force, thereby reducing employment probabilities for worker groups most likely to be affected by the mandate.

Results for all three labor market outcomes are displayed in Table 2 and Figure 5. For brevity, we report only the results for the difference-in-differences parameter $(\Delta)$; for each outcome, the full regression results for the most recent sample period are listed in Appendix C (intended for the online version).

\section{VI.A. Wages}

Before turning to our empirical estimates of relative wage changes, it is useful to consider what constitutes a plausible wage effect of Hawaii's mandate. We assess this by calculating the difference effect $\Delta$ that we would expect to estimate if the growing costs of the mandate for employers were fully offset by an equivalent reduction in wages. We set the cost of the mandate equal to the own-ESI coverage differential between Hawaii and the rest of the United States multiplied by the full cost of ESI coverage in Hawaii. We focus on the second ESI quintile, because it exhibits the largest effect on own ESI coverage and combined own and dependent 
coverage in Figures 3 and 4. The calculations were performed under the assumption that employers pay $85 \%$ of the full direct costs of workers' health insurance in Hawaii and $80 \%$ of the direct costs in other states. ${ }^{22}$ The implied decline in relative wages between the baseline (1979-82) and comparison (2002-05) periods equals 1.6 percent. This represents a very small change in the observed wage gap over our lengthy sample frame, and as such it is unlikely to be detectable with acceptable statistical precision using our placebo criterion.

The estimated state effects for wages in difference form are displayed in the first column of Figure 5 and the top panel of Table 2; the wage regressions were estimated with the log hourly wage as the dependent variable, and the estimated state effects were translated into percentage effects on wages using the standard transformation of the coefficient on a dummy variable in a semi-log equation. The results indicate that wages on average fell slightly (about 3\%) in Hawaii relative to other states over our sample frame (first row, full sample). Across the quintiles, relative wages in Hawaii fell $2.4 \%$ in the first quintile, rose slightly $(1.7 \%)$ in the second quintile, and fell by about $4-7.5 \%$ in the upper three quintiles.

These wage declines are not readily attributable to Hawaii's mandate, for two reasons: (1) the change in wages is wrong-signed in the second quintile (positive rather than negative), and more generally the estimated wage declines in Hawaii are larger in the higher quintiles; these findings are inconsistent with the predictions of the supply-demand framework for assessing the effects of an employer mandate and also with our prior finding of larger ESI effects in the lower quintiles; (2) the estimated Hawaii effect on wage changes is towards the middle of the distribution of placebo estimates for other states, so according to our placebo criterion we are unable to reject the hypothesis that wage changes in Hawaii were the same as in other states.

\footnotetext{
${ }^{22}$ We based these assumptions on tabulations of employee contributions for health insurance plans, using the MEPS-IC data for private-sector establishments in Hawaii and the United States as a whole.
} 
As a robustness check, we performed the same placebo test for wage changes using a sample restricted to workers in the retail industry, who are among the groups most likely to be affected by the mandate. As shown in Appendix B (Figure B4), the results for this group are qualitatively similar to the full sample results.

It is important to note that a conventional statistical test would imply large negative wage effects of Hawaii's mandate: for the full sample, the t-statistic on the appropriate Hawaii*period interaction in a fully interacted specification with clustered standard errors is -2.94 , indicating a high degree of statistical significance for the estimated wage declines in Hawaii. However, applying the same statistical test to the other states effects, we obtain t-statistics that exceed an absolute value of two in 43 of the 50 cases. As noted in Section IV, this over-rejection of the null of no significant differences between states highlights why we use the placebo approach.

These results do not necessarily indicate that Hawaii's ESI mandate had no effect on wages, but rather that the effect is not detectable in our data using acceptable statistical criteria. Our inability to reject the null of no wage effect is unsurprising, given the very small magnitude of the simulated wage offset discussed at the beginning of this sub-section. ${ }^{23}$ Based solely on this analysis one might conclude from our permutation testing approach that our design is not powerful enough to detect effects of Hawaii's mandate on any labor market outcomes using our data. However, the results discussed in the next section indicate otherwise.

\section{VI.B. Low Hours Employment}

The second column of Figure 4 and second panel of Table 2 display results from regressions that test whether there has been a long-run trend toward exempt part-time (low-

\footnotetext{
${ }^{23}$ Our point here is similar to that made by Bhattacharya and Vogt (2000) regarding estimated employment effects of state insurance mandates. Using statistical power functions, they argued that the inability to reject the null of no effects in papers such as Gruber (1994) was largely noninformative.
} 
hours) work in Hawaii relative to other states, once again showing results for the full sample and the breakdown by ESI quintiles. ${ }^{24}$ Individuals are identified as working low hours if they typically work fewer than 20 hours per week, which is the cutoff for determining whether a worker is subject to the provisions of the mandate.

In the full sample, the estimate of the change effect for Hawaii is positive and exceeds the 95th percentile critical value from the distribution of placebo estimates; it thereby meets our standard for statistical significance, indicating that over the entire period the percentage of adults in short-hour jobs grew significantly faster in Hawaii than in other states. The additional results in Figure 4 and Table 2 indicate that this full-sample result is driven primarily by the sub-sample with the lowest probability of receiving ESI. The estimate for this group is statistically significant at the 10 percent level. $^{25}$

The estimated shift toward exempt part-time employment is consistent with findings from past research, including anecdotal evidence cited by the U.S. GAO study (1994, page 15) and limited quantitative evidence provided in Thurston (1997) and Lee et al. (2005). These findings suggest employer avoidance behavior in response to the mandate, which reduces the costs of the mandate and limits its labor market effects. The size of this reduction in mandate costs is economically meaningful, even though the mandate costs themselves are not large. In particular, the estimated increase in part-time work in the first ESI quintile for Hawaii is 3.7 percentage points, compared with an estimated increase in own ESI coverage of 7.1 percentage points (Table 1, Panel C). Assuming that all of the increase in low-hours employment offset the

\footnotetext{
${ }^{24}$ See Appendix A for details regarding the hours variable.

${ }^{25}$ A shift towards low-hours work also is evident in the third quintile. Recall that although the crosssectional gap in ESI coverage was fairly large for this quintile, it did not grow significantly over time. Therefore, this effect on part-time work reflects the rising burden of the mandate associated with rising health insurance costs for groups that have higher coverage rates in Hawaii than in other states.
} 
increase in mandated ESI coverage, had the switch to low-hours employment not occurred, the increase in ESI coverage would have been $10.8(7.1+3.7)$ rather than 7.1 percentage points. The implied reduction in the costs of the mandate is about one-third $(3.7 / 10.8=0.34) .{ }^{26}$

We subjected these findings for low-hours work to some of the same robustness and falsification tests that we applied to the own ESI results in Section V.C. The results are displayed in Appendix B (difference-differences estimate only). First, we estimated the lowhours models for two alternative, intermediate time periods (1990-93 vs. 1979-82, 2002-05 vs. 1990-93) (Figure B5). The results indicate that the increase in low-hours work was restricted to the second half of our sample frame. We also estimated the low-hours model for our sample of government employees (Figure B6). The results suggest a switch to low-hours work in the higher quintile groups ( $3 \mathrm{rd}$ and 4 th; results for the $5^{\text {th }}$ quintile cannot be estimated), which is inconsistent with the expected effects of the mandate and therefore does not falsify our finding for private sector workers.

\section{VI.C. Employment}

The final outcome we consider is employment, which has been the primary focus of recent critiques of employer mandates (Yelowitz 2003; Baicker and Levy 2007; Burkhauser and Simon 2007). The last column of Table 2 and bottom panel of Figure 5 displays results from

\footnotetext{
${ }^{26}$ The estimated increase in low-hours employment is of moderate size compared with its base incidence in the first ESI quintile. The share of low-hours employment in this group ranged from about 10-16 percent across our sample frame (with a downward trend evident over time), and the increase of 3.7 percentage points represents about a $25-35 \%$ increase relative to this base level. Readers may note also that the switch to low-hours employment was larger in the first ESI quintile than in the second, despite the larger increase in ESI in the second quintile (from Table 1). This pattern likely arises because employers' incentives to substitute towards low-hours employment depend not just on the mandate costs but also on detailed characteristics of their production functions that determine the costs of adjusting employees' work schedules. Such costs are likely to be small for the low-skill workers most affected by the mandate.
} 
regressions that use an indicator for employment status as the dependent variable. ${ }^{27}$ The specification of these regressions is similar to the model used for wages and part-time work. However, the sample now consists of all adults 18 to 64 years old (not just those who are employed) and we exclude industry and occupation from the list of controls used in the ESI prediction and outcome equations. The results are similar to the wage regressions, indicating that although conditional employment probabilities declined in Hawaii over time, the changes do not achieve statistical significance at or near the 10 percent level based on our placebo test. ${ }^{28}$ The sole exception is the fourth ESI quintile, for which a 6.6 percentage point decline in employment probabilities was estimated, significant at the $10 \%$ level based on our placebo criterion. Because this group was not subject to significant mandate effects on coverage, we regard this result as reflecting random elements in the data rather than the impact of the mandate.

\section{DISCUSSION AND CONCLUSIONS}

We found that relative ESI coverage rose in Hawaii over time, and the increase was larger for workers with characteristics that imply low coverage rates in the absence of a mandate, consistent with the standard supply/demand theory regarding the effects of employer mandates. This finding meets the stringent standards for statistical significance imposed by our placebo testing framework, suggesting that it is a result of the state's employer mandate rather than random factors at the state level. Our findings regarding alternative coverage sources suggested that coverage as a dependent on ESI programs may have declined by a small amount, reducing the cost burden of the mandate, although this finding does not achieve statistical significance.

\footnotetext{
${ }^{27}$ Individuals are identified as employed if they report working positive hours for pay during the reference week for the monthly CPS files; employment can be private, government, or self-employment.

${ }^{28}$ The t-statistic on the Hawaii*(time period) interaction in a fully interacted specification with clustered standard errors is -2.70 , indicating significance at the $1 \%$ level.
} 
By contrast, we found clear and statistically significant evidence of reductions in coverage through public programs such as Medicaid, which were of a similar magnitude to the increase in ESI among worker groups most affected by the mandate.

Regarding labor market outcomes, the results from our permutation tests suggest no discernable wage effect of the mandate: the changes in Hawaii's distribution of wages as the costs of the mandate rose are statistically indistinguishable from changes in the wage distribution in other states analyzed in a parallel fashion. Relative wages fell in Hawaii over time, but no more so than in many other states, and the decline in relative wages in Hawaii was similar for worker groups that differ sharply in regard to the estimated effect of the mandate on ESI coverage. Consistent with prior fragile findings regarding wage reductions due to Hawaii's mandate (Thurston 1997), these results indicate that any wage reductions arising from the mandate are too small to be detectable in our data.

Although we cannot reliably estimate wage offsets resulting from Hawaii's mandate, it is likely that for some groups, such as low-wage workers for whom wage reductions are constrained by the minimum wage, any wage reductions will not be large enough to fully offset the mandate costs to employers. Under these circumstances, the basic supply and demand framework points to adjustments along other margins. We uncovered evidence of such adjustments, in the form of an increase in the percentage of individuals working less than 20 hours per week, which is the threshold distinguishing covered and exempt worker under Hawaii's mandate. The estimated shift towards low-hours schedules was concentrated among the worker groups that were most affected by the mandate, which supports the interpretation that the shift reflects employers' direct responses to the mandate. Using a similar framework, we found no statistically detectable changes in relative employment probabilities in Hawaii. As with 
our findings for wages, our data and empirical design do not allow us to rule out employment reductions arising from the mandate, especially for workers who face low probabilities of receiving ESI in a voluntary market. However, such effects are small relative to the variation in other unobserved factors that affect cross-state employment trends.

Our results on net suggest that Hawaii's health insurance mandate succeeded in raising ESI coverage rates for worker groups with low coverage rates in an unconstrained environment, but the costs of this coverage expansion were small compared with other factors affecting labor demand across states. Our results regarding declines in public coverage indicate that expanded ESI coverage served largely to shift the coverage burden from public programs to the private sector. While Hawaii is a somewhat unique state in terms of geography, our analyses indicate that it is not an outlier in regard to labor market characteristics, suggesting that ESI mandates may cause limited labor market distortions in other states as well. On the other hand, Hawaii's employer mandate has left the state well short of universal coverage, suggesting a need for alternative approaches to expanding coverage if that is the ultimate policy goal. 


\section{REFERENCES}

Abadie, Alberto, Alexis Diamond, and Jens Hanimueller. 2009. "Synthetic Control Methods for Comparative Case Studies: Estimating the Effect of California's Tobacco Control Program.” Working Paper, Kennedy School of Government. August.

Agsalud, Joshua C. 1982. Testimony before the U.S. Congress, House Committee on Education and Labor. ERISA: Exemption from Preemption for Hawaii Prepaid Health Care Act. $97^{\text {th }}$ Congress, $2^{\text {nd }}$ session, January 7 and 8.

Autor, David, Lawrence Katz, and Melissa Kearney. 2008. "Trends in U.S. Wage Inequality: Revising the Revisionists." Review of Economics and Statistics 90(2, May): 300-323.

Baicker, Katherine and Helen Levy. 2007. "Employer Health Insurance Mandates and the Risk of Unemployment," National Bureau of Economic Research Working Paper No. 13528.

Bhattacharya, Jay, and William Vogt. 2000. "Could We Tell if Health Insurance Mandates Cause Unemployment? A Note on the Literature." Working Paper, Rand Corporation..

Buchmueller, Thomas C., John DiNardo, and Robert G. Valletta. 2002. "Union Effects on Health Insurance Provision and Coverage in the United States." Industrial and Labor Relations Review 55(4, July): 610-627.

Burkhauser, Richard and Kosali Simon. 2007. "Who Gets What From Employer Pay or Play Mandates?” National Bureau of Economic Research Working Paper No. 13578.

Card, David. 1996. "The Effect of Unions on the Structure of Wages: A Longitudinal Analysis." Econometrica 64(4): 957-979.

Dick, Andrew. 1994. "Will Employer Mandates Really Work? Another Look at Hawaii." Health Affairs (Spring): 343-349.

Donald, Stephen G., and Kevin Lang. 2007. "Inference with Difference-in-Differences and Other Panel Data." Review of Economics and Statistics 89(2, May): 221-233.

Fisher, R.A. 1935. The Design of Experiments. Edinburgh: Oliver and Boyd.

Friedman, Emily. 1993. The Aloha Way: Health Care Structure and Finance in Hawaii. Honolulu: Hawaii Medical Service Association Foundation,.

Hansen, Ben B. 2008. "The prognostic analogue of the propensity score." Biometrika 95(2): 481-8. 
Hirsch, Barry T., David A. Macpherson, and Wayne G. Vroman. 2001. "Estimates of Union Density by State." Monthly Labor Review 124(7, July): 51-55 (accompanying data online at www.unionstats.com).

Imbens, Guido W. , and Jeffrey M. Wooldridge. 2009. "Recent Developments in the Econometrics of Program Evaluation." Journal of Economic Literature 47(1): 5-86.

Lee, Sang-Hyop, Gerard Russo, Lawrence H. Nitz, and Abdul Jabbar. 2005. "The Effect of Mandatory Employer-Sponsored Insurance (ESI) on Health Insurance Coverage and Labor Force Utilization in Hawaii: Evidence from the Current Population Survey (CPS) 1994-2004.” Working paper, Department of Economics, University of Hawaii.

Lemieux, Thomas. 2006. "Increasing Residual Wage Inequality: Composition Effects, Noisy Data, or Rising Demand for Skills?” American Economic Review 96 (3, June): 461-498.

Mariner, Wendy K. 1992. "Problems with Employer-provided Health Insurance -- the Employee Retirement Income Security Act and Health Care Reform," New England Journal of Medicine, 1327:1682-1685.

Moulton, Brent. 1990. "An Illustration of a Pitfall in Estimating the Effects of Aggregate Variables on Micro Units." Review of Economics and Statistics 72(2): 334-38.

Neubauer, Dean. 1993. “A Pioneer in Health System Reform,” Health Affairs, 31-39.

Oliver, Thomas. 2004. "State Employer Health Insurance Mandates: A Brief History." Mimeo, California HealthCare Foundation, March. http://www.chcf.org/topics/healthinsurance/ coverageexpansion/index.cfm?itemID=109984.

Summers, Lawrence H. 1989. "Some Simple Economics of Mandated Benefits," American Economic Review, 79(2):177-183.

Thurston, Norman. 1997. "Labor Market Effects of Hawaii’s Mandatory Employer-Provided Health Insurance," Industrial and Labor Relations Review, 51(1): 117-138.

U.S. General Accounting Office. 1994. "Health Care in Hawaii: Implications for National Reform.” Report, GAO/HEHS-94-68, February.

Wooldridge, Jeffrey M. 2006. "Cluster-Sample Methods in Applied Econometrics: An Extended Analysis." Manuscript, Department of Economics, Michigan State University, June.

Yelowitz, Aaron. 2004. "The Economic Impact of Proposition 72 on California Employers." Employment Policies Institute Report, September. 
Figure 1: ESI Premiums in Hawaii

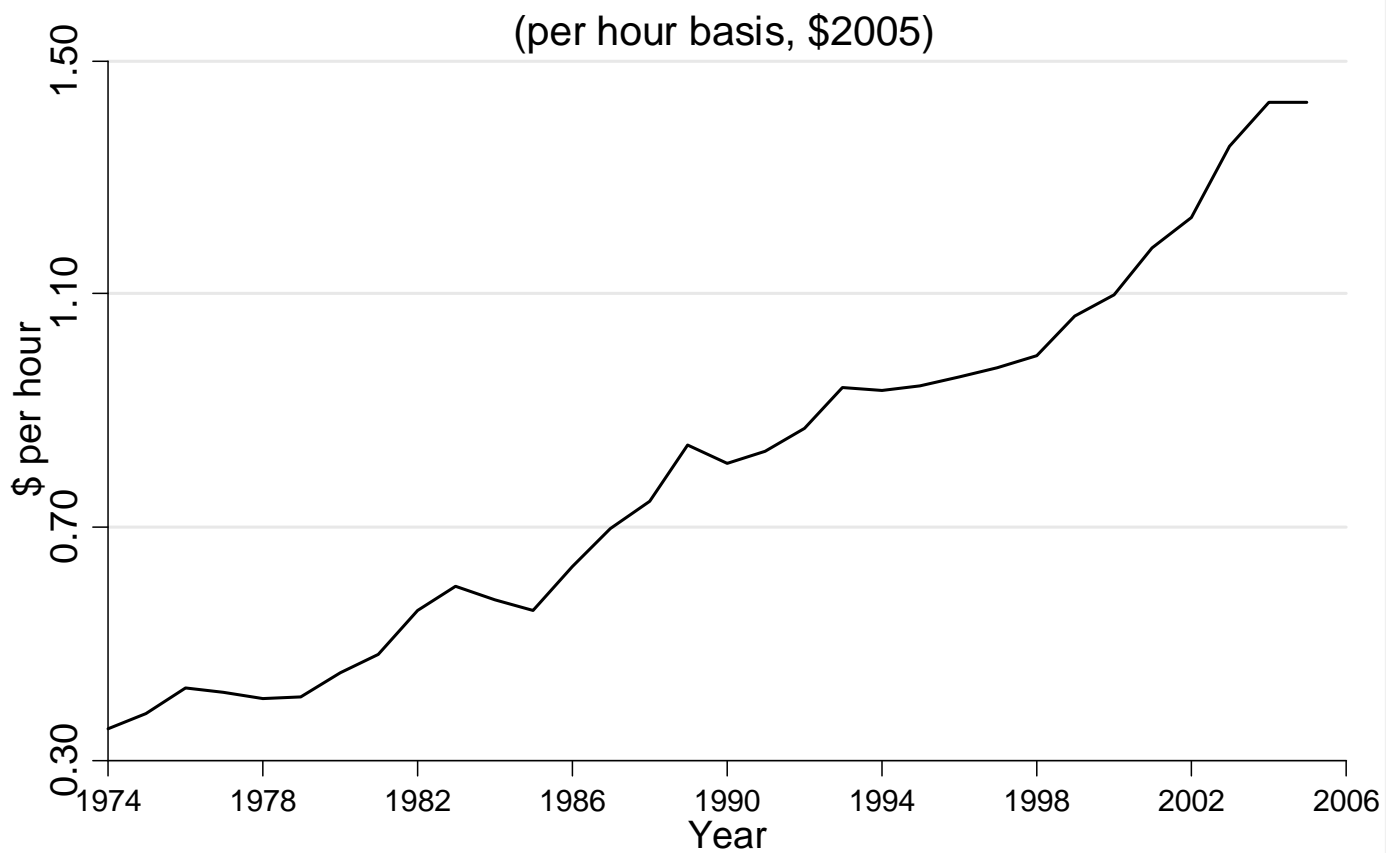

Source: HMSA, single coverage health insurance premium; deflated using the CPI for Honolulu. 
Figure 2: ESI Coverage, by Education, 1979-2005 (private sector employees, age 18-64)
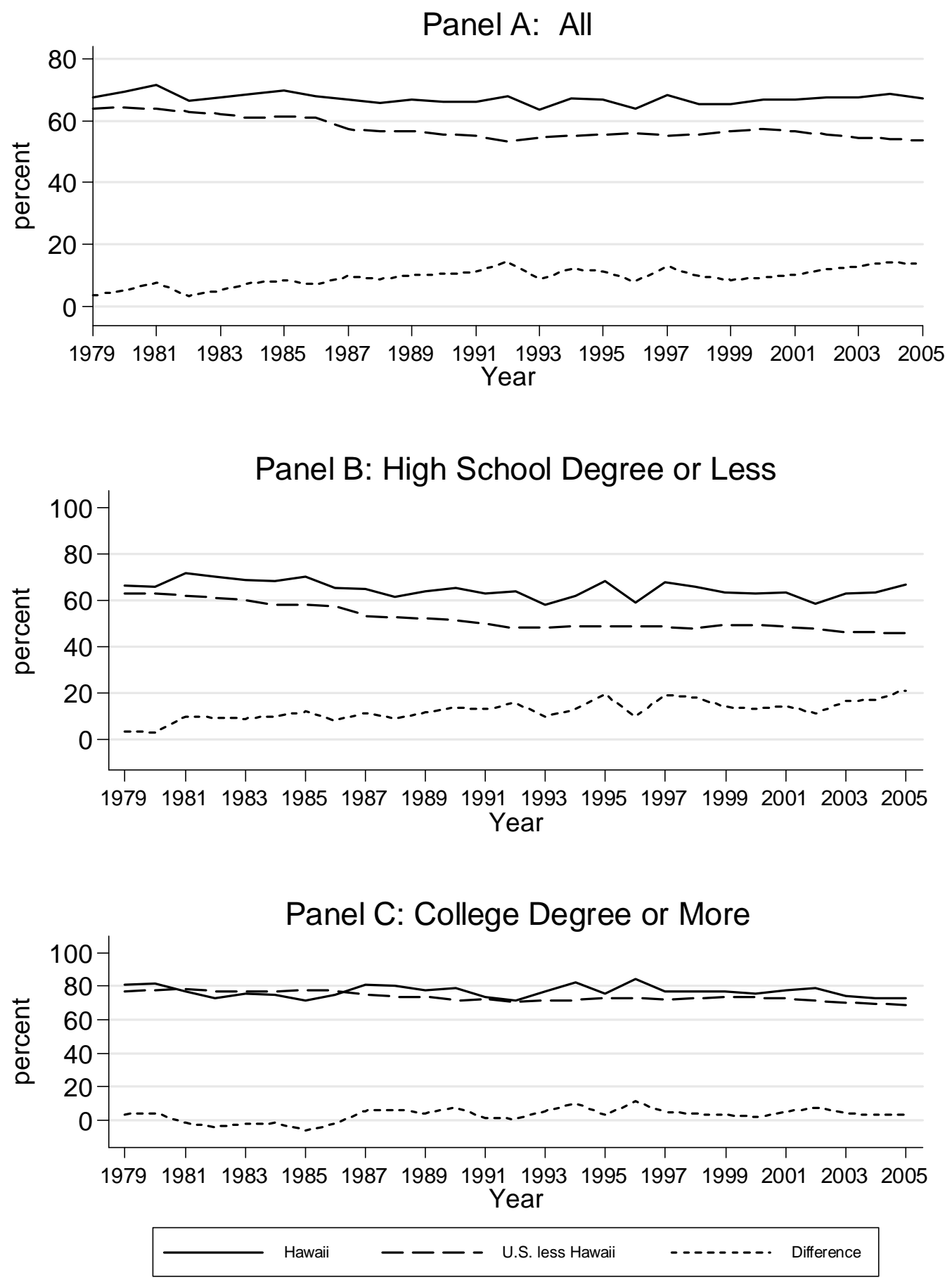

Note: Authors' tabulations (weighted) from March CPS files, 1980-2006. 
Figure 3: State Effects (percentages), Own ESI (by quintile) Estimates for 1979-82, 2002-05, difference (02-05 minus 79-82)
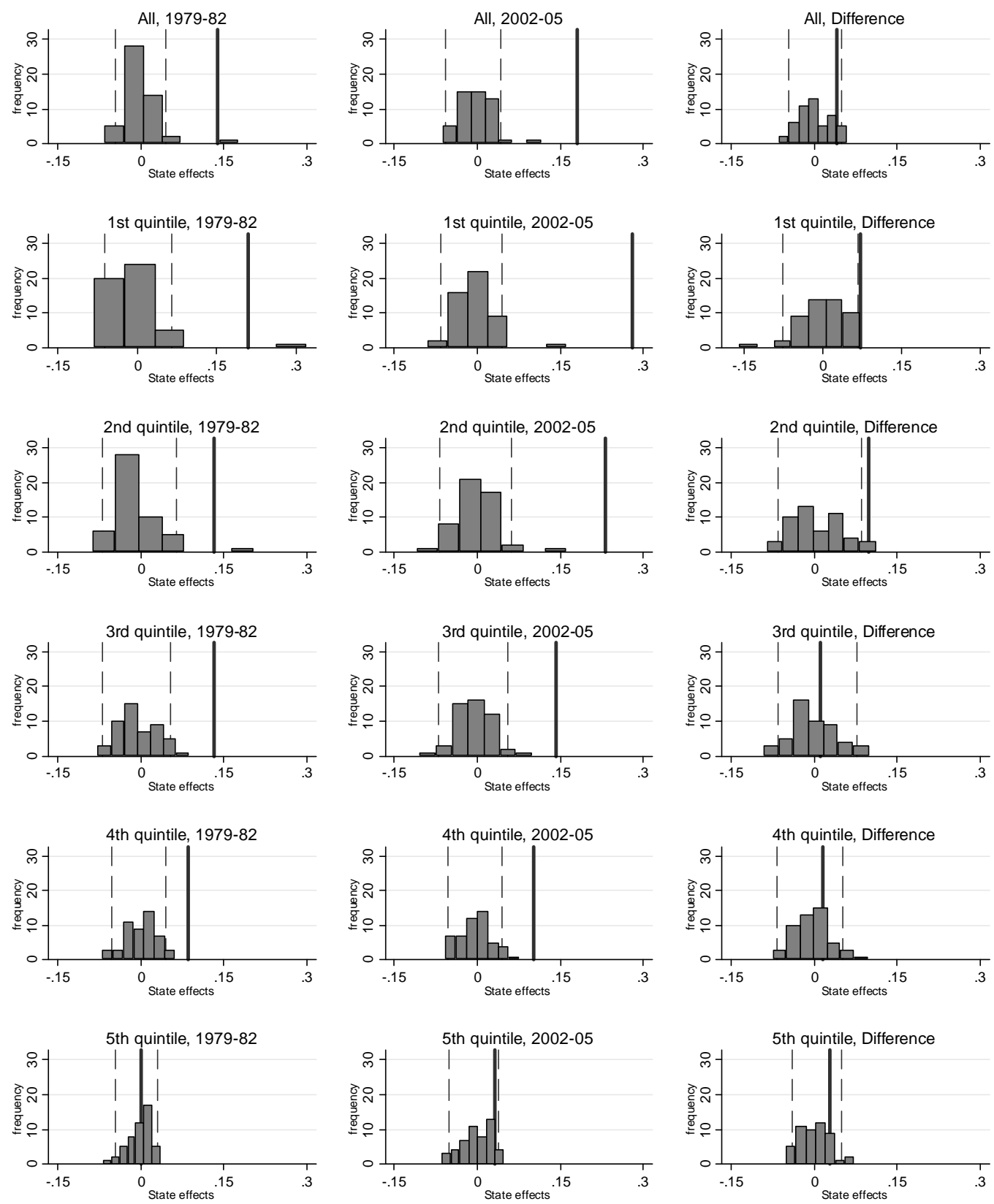

Note: Estimated using March CPS data, private sector workers age 18-64. The dashed lines are the 5th and 95th percentile values (other than Hawaii), the solid line is the Hawaii value. Logit models; covariates include the complete set of demographic/state and job controls (see Table 1). Effects estimated as treatment on the treated, converted to percentages (see text). Quintiles formed using fitted $\operatorname{Pr}(\mathrm{ESI})$, structure estimated for U.S. ex. Hawaii (see text). 
Figure 4: State Effects (percentages), Alternative Coverage (by quintile) Difference estimates (2002-05 minus 1979-82)
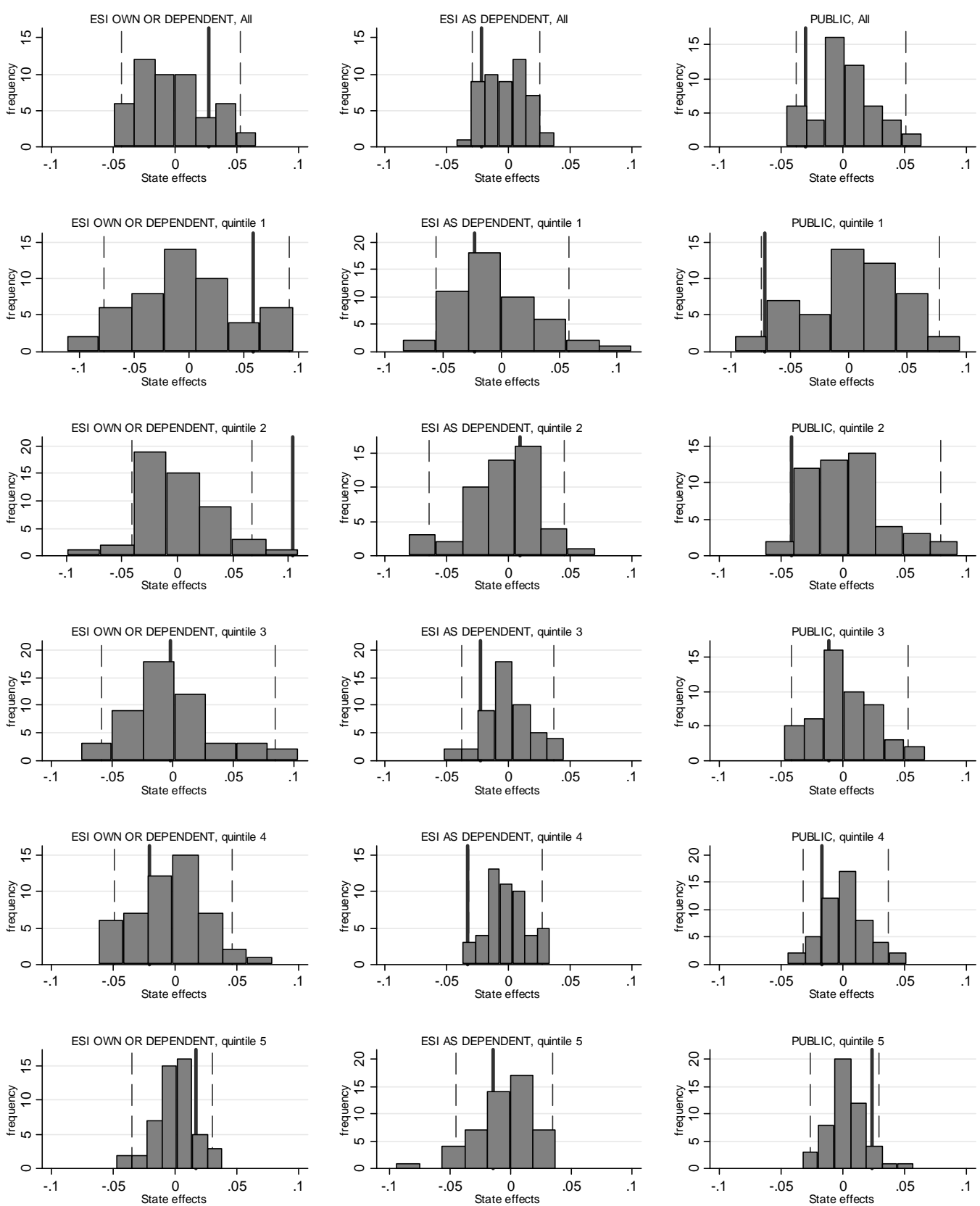

Note: Estimated using March CPS data, private sector workers age 18-64. The dashed lines are the 5th and 95th percentile values (other than Hawaii), the solid line is the Hawaii value. Logit models; covariates include the complete set of demographic/state and job controls (see Table 1). Effects estimated as treatment on the treated, converted to percentages (see text). Quintiles formed using fitted $\operatorname{Pr}(\mathrm{ESI})$, structure estimated for U.S. ex. Hawaii (see text). 
Figure 5: State Effects (percentages), Labor Market Outcomes (by quintile) Difference estimates (2002-05 minus 1979-82)
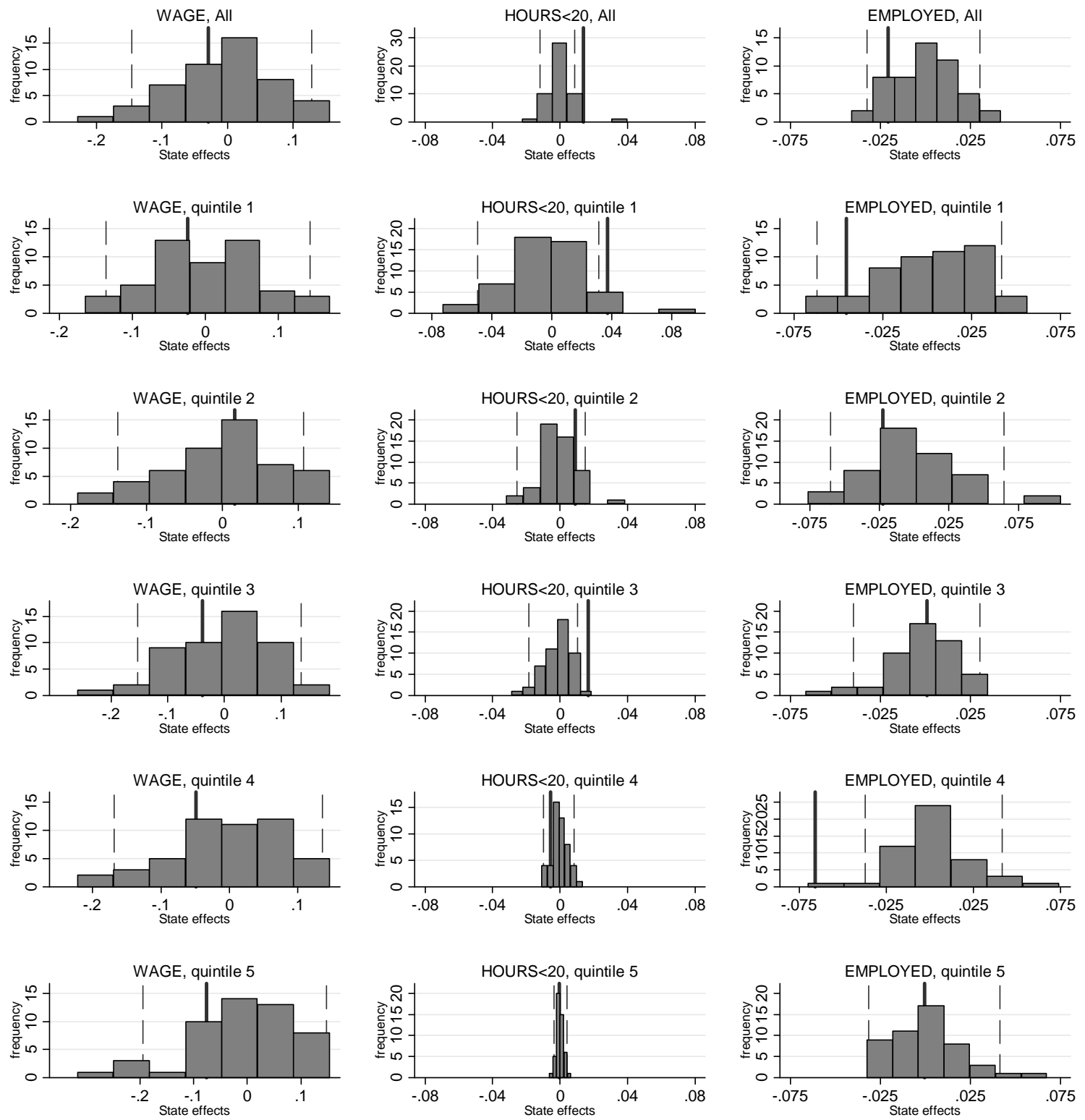

Note: Estimated using CPS MORG data, individuals age 18-64 (private sector workers for wages/hours, all individuals for employment). The dashed lines are the 5th and 95th percentile values (other than Hawaii), the solid line is the Hawaii value. Regressions are log-linear for wages (coefficients converted to \% effects), logit models for $\operatorname{Pr}($ hours $<20$ ) and $\operatorname{Pr}$ (employed) in the current job (effects are treatment on the treated, converted to percentages; see text). Full controls used (see Table 1), except ind/occ excluded from the employment regression. Quintiles formed using fitted $\operatorname{Pr}(\mathrm{ESI})$, structure estimated using March CPS data, U.S. excluding Hawaii obs (see text). 


\section{Table 1: State Effects (percentages), Own ESI Coverage (by quintile) (placebo tests, Hawaii vs. all other states)}

Panel A: 1979-1982

\begin{tabular}{|c|c|c|c|c|c|c|}
\hline & \multirow[t]{2}{*}{$\underline{\text { Full sample }}$} & \multicolumn{5}{|c|}{ ESI Quintiles } \\
\hline & & 1st & 2nd & 3rd & 4th & 5th \\
\hline Hawaii effect & $0.139^{*}$ & $0.209^{*}$ & $0.133^{*}$ & $0.132 * *$ & $0.085^{* *}$ & 0.002 \\
\hline \multicolumn{7}{|c|}{ Placebo effects (other states) } \\
\hline $95^{\text {th }}$ percentile & 0.046 & 0.066 & 0.065 & 0.055 & 0.045 & 0.031 \\
\hline $5^{\text {th }}$ percentile & -0.046 & -0.062 & -0.070 & -0.070 & -0.052 & -0.046 \\
\hline
\end{tabular}

Panel B: 2002-2005

Full sample

ESI Quintiles

\begin{tabular}{lllllll} 
& & 1st & 2nd & 3rd & 4th & 5th \\
\hline $\begin{array}{l}\text { Hawaii effect } \\
\text { Placebo tests (other states) }\end{array}$ & $0.181^{* *}$ & $0.281^{* *}$ & $0.232^{* *}$ & $0.142^{* *}$ & $0.101^{* *}$ & 0.031 \\
$\quad$ & & & & & \\
$95^{\text {th }}$ percentile & 0.043 & 0.045 & 0.062 & 0.054 & 0.045 & 0.039 \\
$5^{\text {th }}$ percentile & -0.057 & -0.067 & -0.069 & -0.070 & -0.054 & -0.052 \\
\hline
\end{tabular}

Panel C: Difference (2002-05 minus 1979-82)

Full sample ESI Quintiles

\begin{tabular}{|c|c|c|c|c|c|c|}
\hline \multirow{2}{*}{\multicolumn{2}{|c|}{$\underline{\text { Full sample }}$}} & \multicolumn{5}{|c|}{ ESI Quintiles } \\
\hline & & 1st & 2nd & 3rd & 4th & 5th \\
\hline Hawaii effect & 0.042 & $0.071^{*}$ & $0.099 *$ & 0.011 & 0.016 & 0.030 \\
\hline \multicolumn{7}{|c|}{ Placebo tests (other states) } \\
\hline $95^{\text {th }}$ percentile & 0.051 & 0.067 & 0.087 & 0.077 & 0.052 & 0.049 \\
\hline $5^{\text {th }}$ percentile & -0.046 & -0.076 & -0.065 & -0.066 & -0.068 & -0.040 \\
\hline
\end{tabular}

Note: Estimated using March CPS data, private sector workers age 18-64, controlling for demographic, state, and job characteristics. The demographic characteristics are education (5 categories), a quartic in age, gender, gender by age quartic interactions, married, married by gender interaction, race/ethnicity (4 categories), residence in an urban area, and veteran status. State characteristics (annual) include union density plus the values of the real minimum wage and real GDP growth. The job characteristics are industry (13) and occupation (11) categories (see Appendix B). Effects are treatment on the treated, converted to percentage effects (see text). Quintiles formed using fitted $\operatorname{Pr}(\mathrm{ESI})$, structure estimated using U.S. excluding Hawaii observations (see discussion in the text).

$* * \mathrm{p}<0.05, * \mathrm{p}<0.10$ (two-tailed tests based on the distribution of placebo effects) 
Table 2: State Effects (percentages), Labor Market Outcomes (by quintile)

Difference estimates (2002-05 minus 1979-82)

(placebo tests, Hawaii vs. all other states)

Panel A: In(hourly wage) (private sector workers, age 18-64)

\begin{tabular}{|c|c|c|c|c|c|c|}
\hline & \multirow[t]{2}{*}{$\underline{\text { Full sample }}$} & \multicolumn{5}{|c|}{ ESI Quintiles } \\
\hline & & 1st & 2nd & 3rd & 4th & 5th \\
\hline Hawaii effect & -0.035 & -0.034 & -0.005 & -0.044 & -0.070 & -0.092 \\
\hline \multicolumn{7}{|c|}{ Placebo effects (other states) } \\
\hline $95^{\text {th }}$ percentile & 0.089 & 0.121 & 0.093 & 0.101 & 0.096 & 0.111 \\
\hline $5^{\text {th }}$ percentile & -0.136 & -0.125 & -0.119 & -0.136 & -0.155 & -0.189 \\
\hline
\end{tabular}

Panel B: $\operatorname{Pr}($ weekly hours<20) (private sector workers, age 18-64)

\begin{tabular}{|c|c|c|c|c|c|c|}
\hline & \multirow[t]{2}{*}{$\underline{\text { Full sample }}$} & \multicolumn{5}{|c|}{ ESI Quintiles } \\
\hline & & 1st & 2nd & 3rd & 4th & 5th \\
\hline Hawaii effect & $0.014^{*}$ & $0.037^{*}$ & 0.009 & $0.017^{*}$ & -0.006 & 0.000 \\
\hline \multicolumn{7}{|c|}{ Placebo tests (other states) } \\
\hline $95^{\text {th }}$ percentile & 0.009 & 0.031 & 0.015 & 0.011 & 0.008 & 0.004 \\
\hline $5^{\text {th }}$ percentile & -0.012 & -0.049 & -0.026 & -0.019 & -0.010 & -0.003 \\
\hline
\end{tabular}

Panel C: Pr(employed) (all individuals age 18-64)

\begin{tabular}{|c|c|c|c|c|c|c|}
\hline \multirow{2}{*}{\multicolumn{2}{|c|}{$\underline{\text { Full sample }}$}} & \multicolumn{5}{|c|}{ ESI Quintiles } \\
\hline & & 1st & 2nd & 3rd & 4th & 5th \\
\hline Hawaii effect & -0.021 & -0.045 & -0.022 & 0.001 & $-0.066^{*}$ & 0.000 \\
\hline \multicolumn{7}{|c|}{ Placebo tests (other states) } \\
\hline $95^{\text {th }}$ percentile & 0.030 & 0.042 & 0.065 & 0.030 & 0.042 & 0.041 \\
\hline $5^{\text {th }}$ percentile & -0.032 & -0.062 & -0.060 & -0.040 & -0.037 & -0.031 \\
\hline
\end{tabular}

Note: Estimated using CPS MORG data, individuals age 18-64 (private sector workers for wages/hours, all individuals for employment). Regressions are log-linear for wages (coefficients converted to \% effects), logit models for $\operatorname{Pr}($ hours $<20$ )and $\operatorname{Pr}($ employed) in current job (effects are treatment on the treated, converted to percentages; see text). Full controls used (see Table 1), except ind/occ excluded from the employment regression. Quintiles formed using fitted $\operatorname{Pr}(\mathrm{ESI})$, structure estimated using March CPS data, U.S. excluding Hawaii obs (see text).

$* * \mathrm{p}<0.05, * \mathrm{p}<0.10$ (two-tailed tests based on the distribution of placebo effects) 
Appendix A: CPS March and MORG Data

Our data are from the Current Population Survey's Annual Demographic Supplement (conducted each year in March, hence referred to as the March CPS) and the Monthly Outgoing Rotation Group (MORG) files. We used the processed March files from Unicon Research Corporation (www.unicon.com) and the MORG files from the National Bureau of Economic Research (www.nber.org/data/morg.html). We describe the characteristics of each source and our specific data choices in detail here. For each data set, the analyses are primarily limited to individuals between the ages of 18 and 64 who are employed by a private sector firm; the exceptions include the employment analyses, for which the sample is all individuals age 18-64, and selected analyses that focus on government workers (again age 18-64). All calculations are weighted using each survey's sampling weights.

\section{March CPS Health Insurance and Pension Data}

We use the March CPS data for our analyses of employer-sponsored health insurance coverage (ESI). Since the 1980 survey, respondents have been asked about health insurance coverage on their longest job held in the preceding year, but the specifics of the question have changed over time. Before the 1988 survey, the ESI question was posed to all working individuals. After 1988, the question was posed to all individuals who had health insurance coverage in their own name. This change in definition creates a series break for tabulations of health insurance coverage, and the Census has chosen not to release such tabulations for calendar years prior to 1987. However, Census Bureau correspondence available in the Unicon data documentation indicates that the impact of the 1988 questionnaire change was more significant for the measurement of sources of health insurance other than ESI (primarily private coverage other than ESI). 
Beginning in 1995, respondents were asked a series of verification questions if their initial response indicated that they were not covered by ESI; additional verification questions were added in 2000. The verification questions increase estimated ESI coverage by an amount that is small but nontrivial from the perspective of national coverage totals. To attain the highest consistency across our sample frame, we used an ESI variable that is defined without reliance on the verification questions, although we ascertained in preliminary analyses that using the verification questions does not materially affect our results.

The March CPS files also provide data on health insurance sources other than own ESI, including ESI as a dependent, other sources of private coverage, and coverage through government programs (primarily Medicare, Medicaid, and programs for military veterans). Prior to survey year 1995 (reference year 1994), information on private coverage sources other than ESI is unavailable in some years and not consistently measured over time, with a notable break in survey year 1988. We therefore are unable to form and directly analyze measures of overall private coverage, total coverage, and uninsurance rates. However, we formed and analyze a series for ESI coverage as a dependent. This variable is directly identified in the data beginning with the 1995 survey. For prior years, we identify it by combining information on ESI coverage in any form (own or dependent) and own ESI coverage: individuals with ESI coverage but not own ESI are labeled as having ESI as a dependent. Throughout the sample frame, we eliminate overlapping coverage from the definition of the ESI variables; individuals with own and dependent ESI are labeled as having own ESI only. We also formed and analyze a series representing coverage through any government source, which is measured consistently over time in the March data files. We exclude overlapping coverage for this variable as well (see footnote 17 in the text). 
The analysis of pension outcomes discussed in section V.C. relied on two pension variables that are consistently defined over our CPS sample frame. These variables measure whether an individual's employer offers pensions to any employees and whether the individual is covered by the pension plan. Both of these indicator variables are defined relative to the complete sample; because an individual's employer must offer a pension plan in order for the individuals to be covered, the share of individuals whose employers offer pensions is an upperbound for the share who are covered by a pension. In our sample, the weighted means for these two variables across all years are in the range of $0.5-0.55$ for pension availability and 0.4 for pension coverage. MORG Data (variable definitions, top-coding, and imputation)

We use the MORG data for our analyses of wage, hours, and employment outcomes. As noted in the text (footnote 5), compared with the March data, the MORG provides larger sample sizes for more precise point-in-time measures of these variables. (We conducted preliminary outcome analyses using the March data and found results that were similar but less precise than those obtained using the MORG data, which is as expected given the smaller sample sizes in the March data.) Our hourly wage variable is defined as reported hourly earnings for those paid by the hour and usual weekly earnings divided by usual weekly hours for salaried employees. We used the CPI for all urban consumers to deflate hourly wages and other dollar-denominated figures, using the CPI for the Honolulu metro area to deflate the Hawaii figures and the all-U.S. series for other states.

We limited the wage analyses to individuals whose hourly wage is greater than $\$ 1$ (in 2005 dollars); this is similar to but slightly less restrictive than Lemieux's rule based on an hourly wage of $\$ 1$ in 1979 dollars, to account for the possibility of extensive sub-minimum wage 
(tipped) work in Hawaii. We multiplied the value of top-coded earnings observations by 1.4; this largely follows Lemieux (2006), with the exception that for the sake of consistency over time, we did not rely on the higher topcode enabled by the use of unedited earnings values for the years 1989-1993.

We also relied on the usual weekly hours variable to identify individuals who work fewer than 20 hours per week. Autor, Katz, and Kearney (2008) noted that this hours variable is not consistently available over time, causing missing observations for the 7-9 percent of the sample after 1994 who report that their hours of work vary. We excluded these observations from the sample rather than follow Autor et al's approach of relying on a variable that measures hours worked at all jobs during the reference week, because we need precise information on weekly hours at sample members' primary job in order to analyze the incidence of low-hours employment. As noted in the text, we obtain similar results for the hours analysis when we use the alternative variable based on hours worked in all jobs (the same is true for the wage analysis).

As discussed by Lemieux (2006) and Autor, Katz, and Kearney (2008), the incidence of imputed values of earnings and hours is substantial in both CPS data sources and has grown over time. Because the Census "hot deck" matching procedure used for imputation does not restrict donor matches to individuals in the same state, our results, which focus on one small state, could be substantially biased if we included imputed observations. We therefore dropped observations with imputed values of earnings from the analysis of earnings and observations with imputed values of hours worked from the analysis of low-hours work. ${ }^{29}$ We followed the procedures outlined in Lemieux (2006) for identifying imputed earnings observations (including the

\footnotetext{
${ }^{29}$ Because the frequency of imputation is much higher for earnings that it is for hours, our analysis samples are larger for the low-hours equations (see the observation counts for the cross-section equations reported in Appendix C).
} 
comparison of unedited and edited earnings values during the years 1989-1993, when the earnings imputation flags are incorrect). Supplementary analyses conducted for various specifications indicated that the results are similar when imputed values are included.

Industry and Occupation Codes

Most of our analyses include industry and occupation controls (see Appendix B, Table B1, for the categories). These definitions have changed over time, with especially large changes in the 2003 data year, due to the switch to the new NAICS codes. We formed consistent broad categories over time based on a comprehensive examination of the codes and consequent reclassification of some industry categories. These recoding schemes are available on request. 
Appendices B and C: SUPPLEMENTAL RESULTS

NOT FOR PUBLICATION 
Appendix Table B1: Population Characteristics, Hawaii vs. Other States (mean values; calculated from March CPS files for 1980-83 and 2003-06)

$\underline{\text { Variable }}$

Age (years)

Married

Female

MSA

Vet
1979-1982 (reference years) $2002-2005$ (reference years)

U.S. ex.

Hawaii

35.7
Hawaii

35.2
U.S. ex.

Hawaii

38.3

(shares)

\begin{tabular}{llll}
\hline 0.574 & 0.598 & 0.506 & 0.540 \\
0.506 & 0.450 & 0.482 & 0.470 \\
0.304 & 0.666 & 0.755 & 0.704 \\
0.139 & 0.188 & 0.065 & 0.071
\end{tabular}

Education

$\begin{array}{rllll}<\text { High School } & 0.147 & 0.212 & 0.075 & 0.127 \\ \text { High School } & 0.388 & 0.396 & 0.319 & 0.320 \\ \text { Some College } & 0.294 & 0.246 & 0.344 & 0.304 \\ \text { College Grad } & 0.111 & 0.089 & 0.206 & 0.179 \\ >\text { College } & 0.060 & 0.057 & 0.057 & 0.070\end{array}$

Race/Ethnicity

$\begin{array}{rllll}\text { White } & 0.290 & 0.825 & 0.176 & 0.685 \\ \text { Black } & 0.007 & 0.097 & 0.012 & 0.109 \\ \text { Hispanic } & 0.022 & 0.058 & 0.068 & 0.146 \\ \text { Other } & 0.681 & 0.020 & 0.744 & 0.059\end{array}$

\section{Nativity}

U.S.-born

$\mathrm{n} / \mathrm{a}$

$\mathrm{n} / \mathrm{a}$

0.839

Foreign-born citizen

$\mathrm{n} / \mathrm{a}$

$\mathrm{n} / \mathrm{a}$

0.769

0.057

Non-citizen

$\mathrm{n} / \mathrm{a}$

$\mathrm{n} / \mathrm{a}$

0.133

0.104

Firm size

$\begin{array}{rllll}<10 \text { emps } & \mathrm{n} / \mathrm{a} & \mathrm{n} / \mathrm{a} & 0.164 & 0.155 \\ 10-24 \text { emps } & \mathrm{n} / \mathrm{a} & \mathrm{n} / \mathrm{a} & 0.127 & 0.118 \\ 25-99 \text { emps } & \mathrm{n} / \mathrm{a} & \mathrm{n} / \mathrm{a} & 0.180 & 0.156 \\ 100-499 \text { emps } & \mathrm{n} / \mathrm{a} & \mathrm{n} / \mathrm{a} & 0.154 & 0.151 \\ 500+\text { emps } & \mathrm{n} / \mathrm{a} & \mathrm{n} / \mathrm{a} & 0.376 & 0.421\end{array}$

(continued) 
Appendix Table B1 (continued)

Variable

dustry

\section{Industry}

Agriculture

Mining

Construction

Manufact. (non-dur)

Manufact. (dur.)

TCPU

Whlsle Trade

Retail Trade

F.I.R.E.

Business Services

Personal Services

Entertainment Serv.

Prof. Services
1980-1983 (survey years)

U.S. ex.

Hawaii
2003-2006 (survey years)

U.S. ex.

Hawaii

$\underline{\text { Hawaii }} \underline{\text { Hawaii }}$

\section{(shares)}

\begin{tabular}{|c|c|c|c|}
\hline 0.045 & 0.021 & 0.017 & 0.011 \\
\hline 0.001 & 0.013 & 0.001 & 0.005 \\
\hline 0.077 & 0.063 & 0.093 & 0.077 \\
\hline 0.060 & 0.115 & 0.024 & 0.057 \\
\hline 0.024 & 0.172 & 0.021 & 0.096 \\
\hline 0.086 & 0.070 & 0.080 & 0.070 \\
\hline 0.054 & 0.048 & 0.036 & 0.038 \\
\hline 0.244 & 0.194 & 0.150 & 0.142 \\
\hline 0.111 & 0.070 & 0.077 & 0.080 \\
\hline 0.061 & 0.045 & 0.085 & 0.077 \\
\hline 0.085 & 0.038 & 0.187 & 0.103 \\
\hline 0.015 & 0.012 & 0.019 & 0.018 \\
\hline 0.135 & 0.139 & 0.208 & 0.225 \\
\hline
\end{tabular}

\section{Occupation}

$\begin{array}{rrrrr}\text { Managerial } & 0.097 & 0.090 & 0.124 & 0.128 \\ \text { Professional } & 0.105 & 0.098 & 0.114 & 0.135 \\ \text { Technical } & 0.015 & 0.018 & 0.020 & 0.029 \\ \text { Sales } & 0.103 & 0.082 & 0.131 & 0.129 \\ \text { Administrative } & 0.195 & 0.187 & 0.159 & 0.148 \\ \text { Services } & 0.196 & 0.134 & 0.225 & 0.163 \\ \text { d/craft/repair } & 0.117 & 0.142 & 0.097 & 0.090 \\ \text { per/fab/labor } & 0.059 & 0.135 & 0.041 & 0.086 \\ \text { Trans/movers } & 0.039 & 0.042 & 0.044 & 0.045 \\ \text { dlers/cleaners } & 0.042 & 0.054 & 0.030 & 0.038 \\ \text { Farm } & 0.032 & 0.016 & 0.015 & 0.009\end{array}$

Sample size

2,477

230,619

4,507

297,649

Note: Authors' calculations from March CPS data, private sector workers age 18-64 (weighted). 
Figure B1: State Effects (percentages), Own ESI Coverage (by quintile) Difference estimates (90-93 vs. 79-82, 02-05 vs. 90-93)
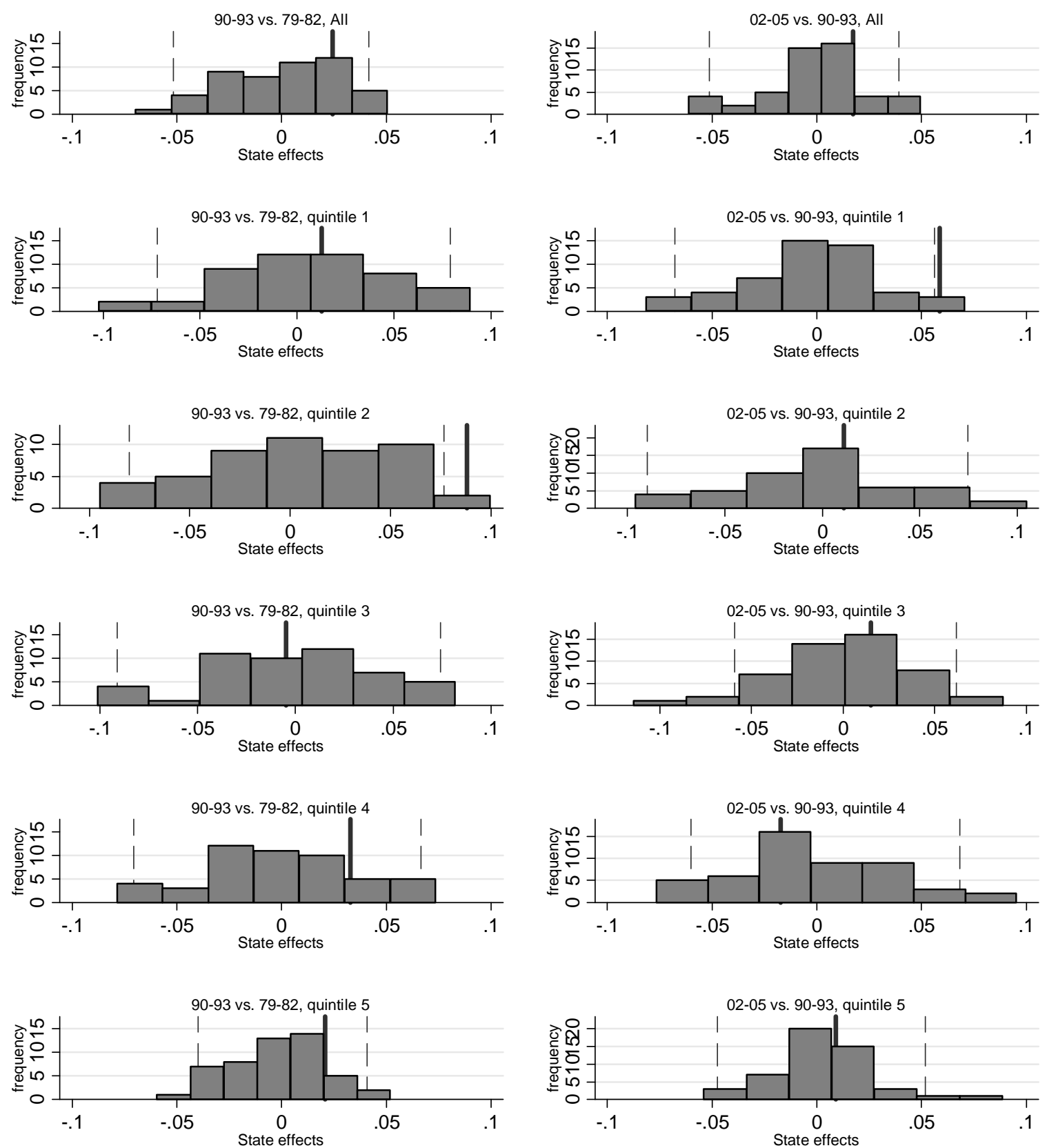

Note: Estimated using March CPS data, private sector workers age 18-64. The dashed lines are the 5th and 95th percentile values (other than Hawaii), the solid line is the Hawaii value. Logit models; covariates include the complete set of demographic/state and job controls (see Table 1). Effects estimated as treatment on the treated, converted to percentages (see text). Quintiles formed using fitted $\operatorname{Pr}(\mathrm{ESI})$, structure estimated for U.S. ex. Hawaii (see text). 
Figure B2: State Effects (percentages), Pensions (by quintile)

Difference estimates (2002-05 minus 1979-82)
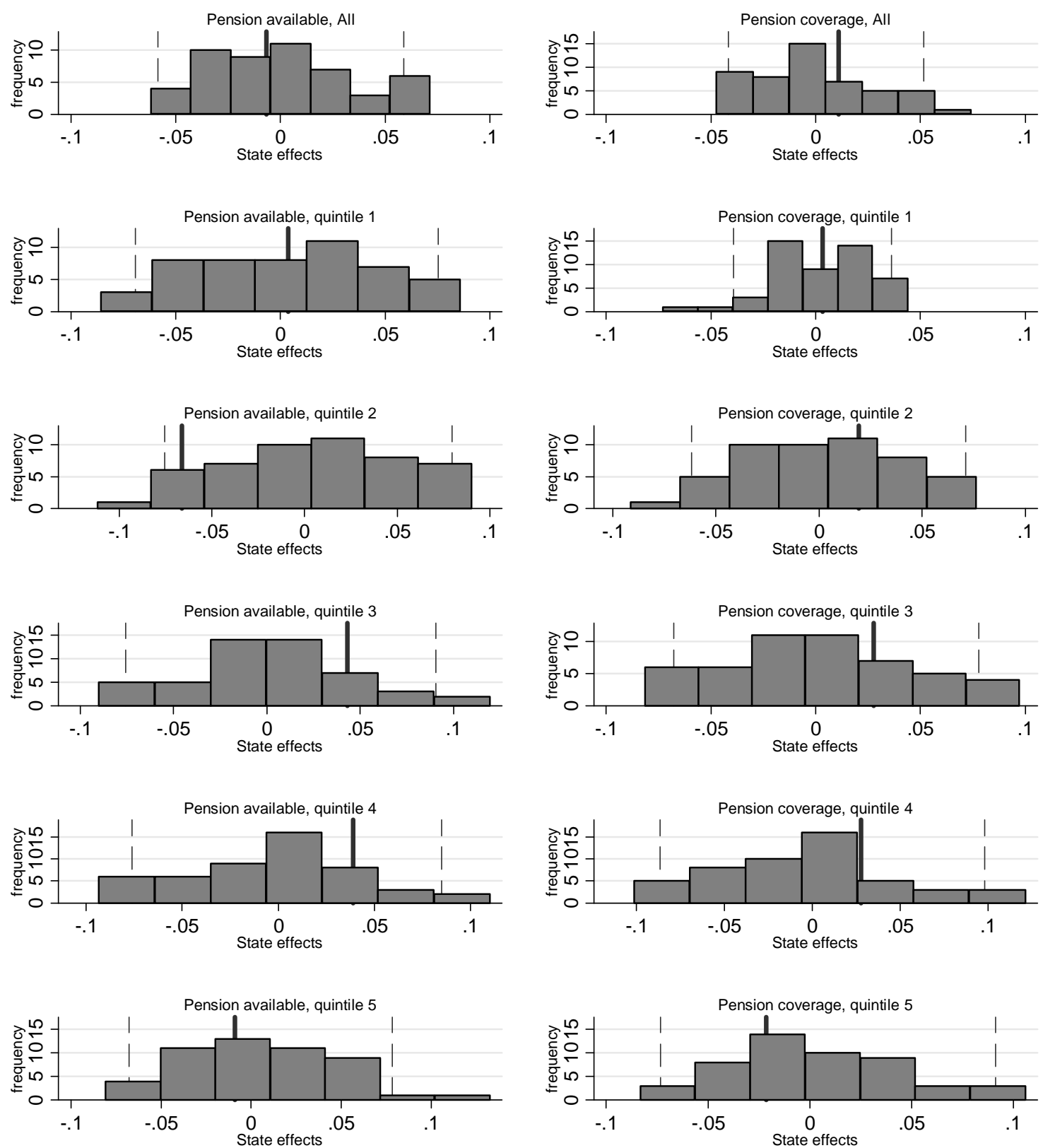

Note: Estimated using March CPS data, private sector workers age 18-64. The dashed lines are the 5th and 95th percentile values (other than Hawaii), the solid line is the Hawaii value. Logit models; covariates include the complete set of demographic/state and job controls (see Table 1). Effects estimated as treatment on the treated, converted to percentages (see text). Quintiles formed using fitted $\operatorname{Pr}($ pension), structure estimated for U.S. ex. Hawaii (see text). 
Figure B3: State Effects (percentages), Own ESI Coverage (by quintile) GOVERNMENT EMPLOYEES

Estimates for 1979-82, 2002-05, difference (02-05 minus 79-82)
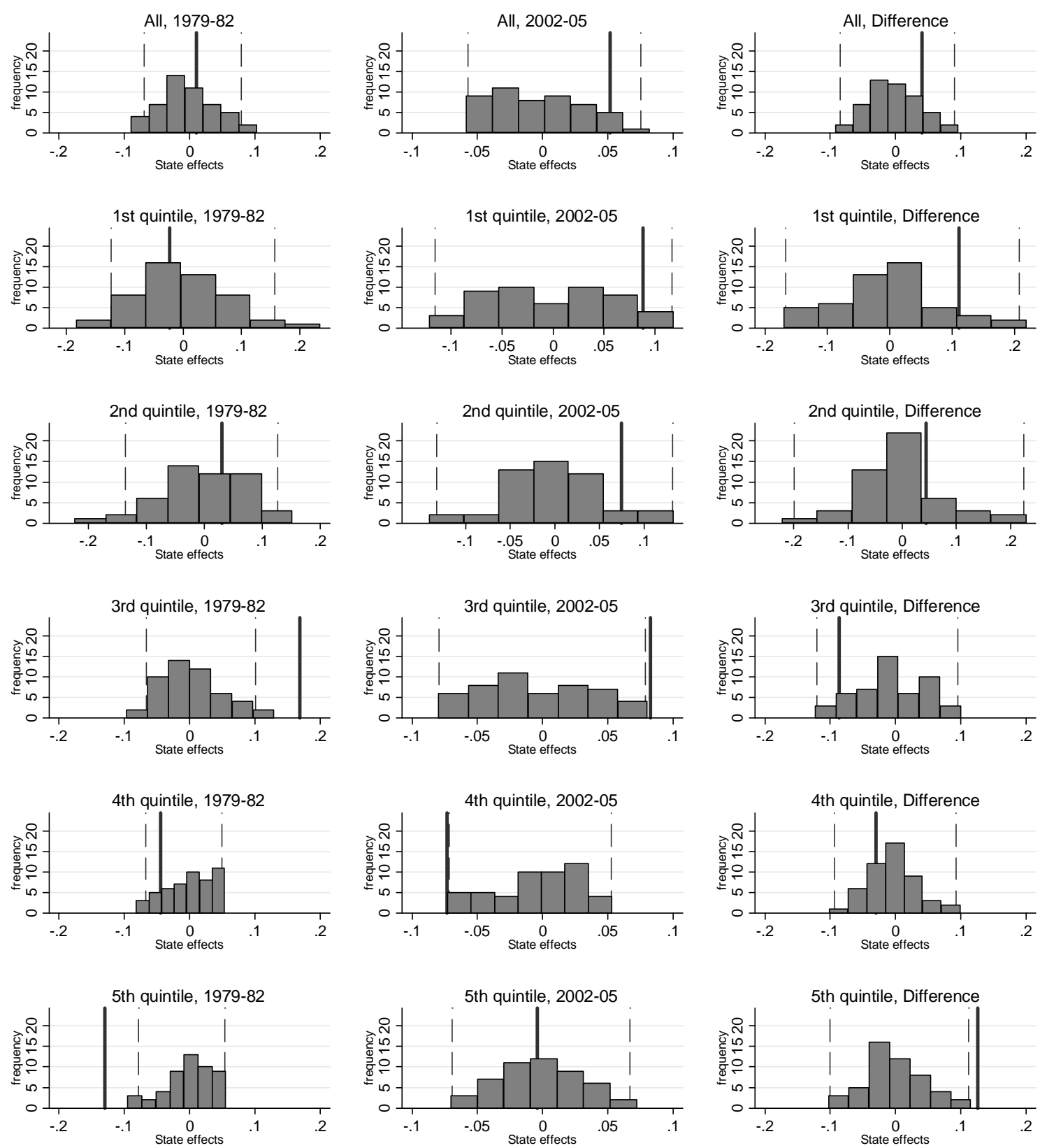

Note: Estimated using March CPS data. The thin dotted lines are the 2.5 and 97.5 percentile values (other than Hawaii), the thick solid line is the Hawaii value. Logit models; covariates include the complete set of demographic/state and job controls (see Table 1), except industry/occupation. Effects estimated as treatment on the treated (see text). Quintiles formed using fitted $\operatorname{Pr}(\mathrm{ESI})$ (government employees only), structure estimated for U.S. ex. Hawaii (see text). 
Figure B4: State Effects, Wages (by quintile)

RETAIL

Difference estimates (2002-05 minus 1979-82)
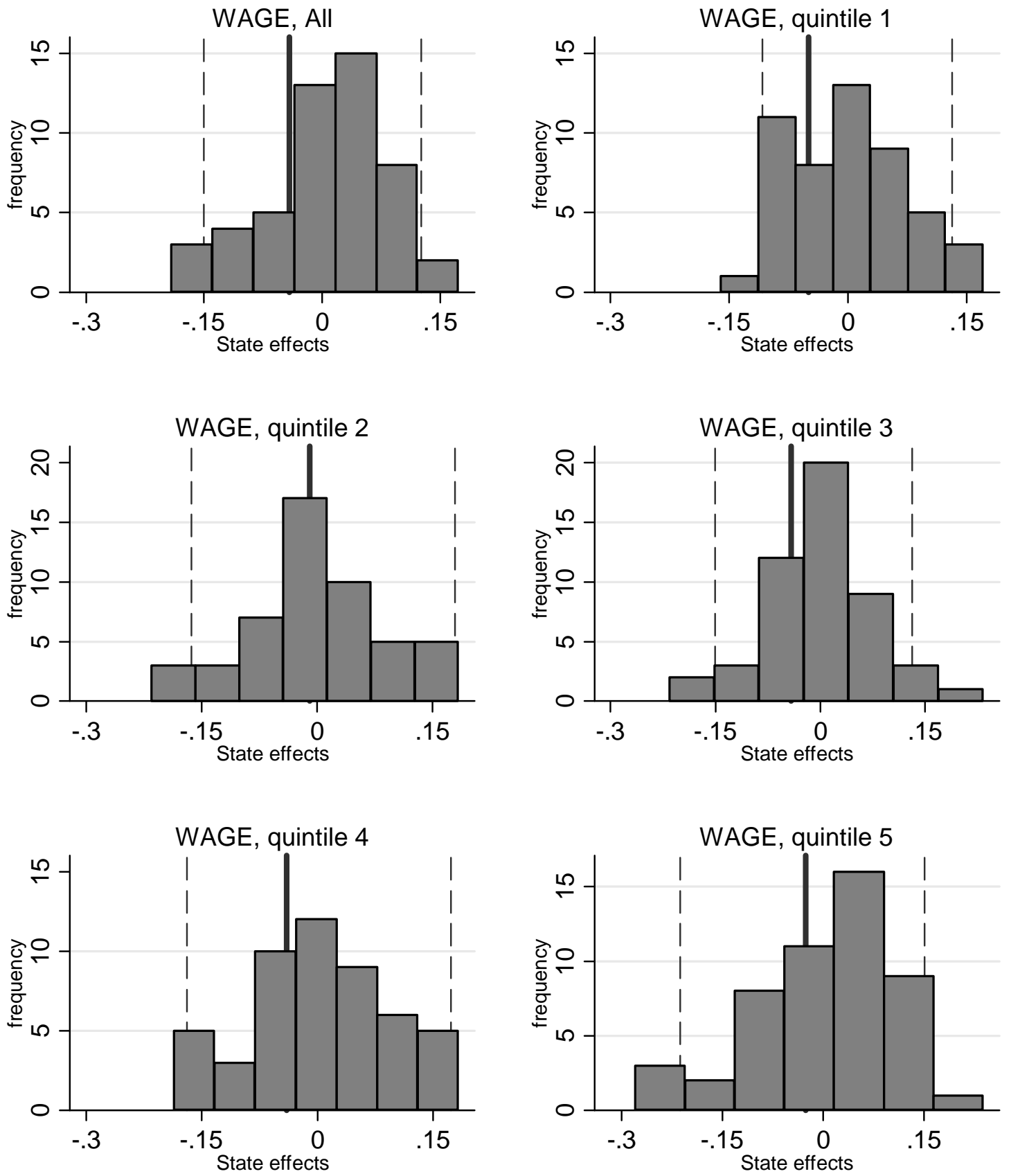

Note: Estimated using CPS MORG data, individuals age 18-64 (retail employees only).

The dashed lines are the 5th and 95th percentile values (other than Hawaii), the solid line is the Hawaii value. Regressions are log-linear for wages (coefficients converted to \% effects). Full controls used (see Table 1), except industry and occupation. Quintiles formed using March CPS, fitted Pr(ESI), structure estimated for U.S. ex. Hawaii (see text). 
Figure B5: State Effects (percentages), $\operatorname{Pr}($ hours $<20$ ) (by quintile) Difference estimates (90-93 vs. 79-82, 02-05 vs. 90-93)
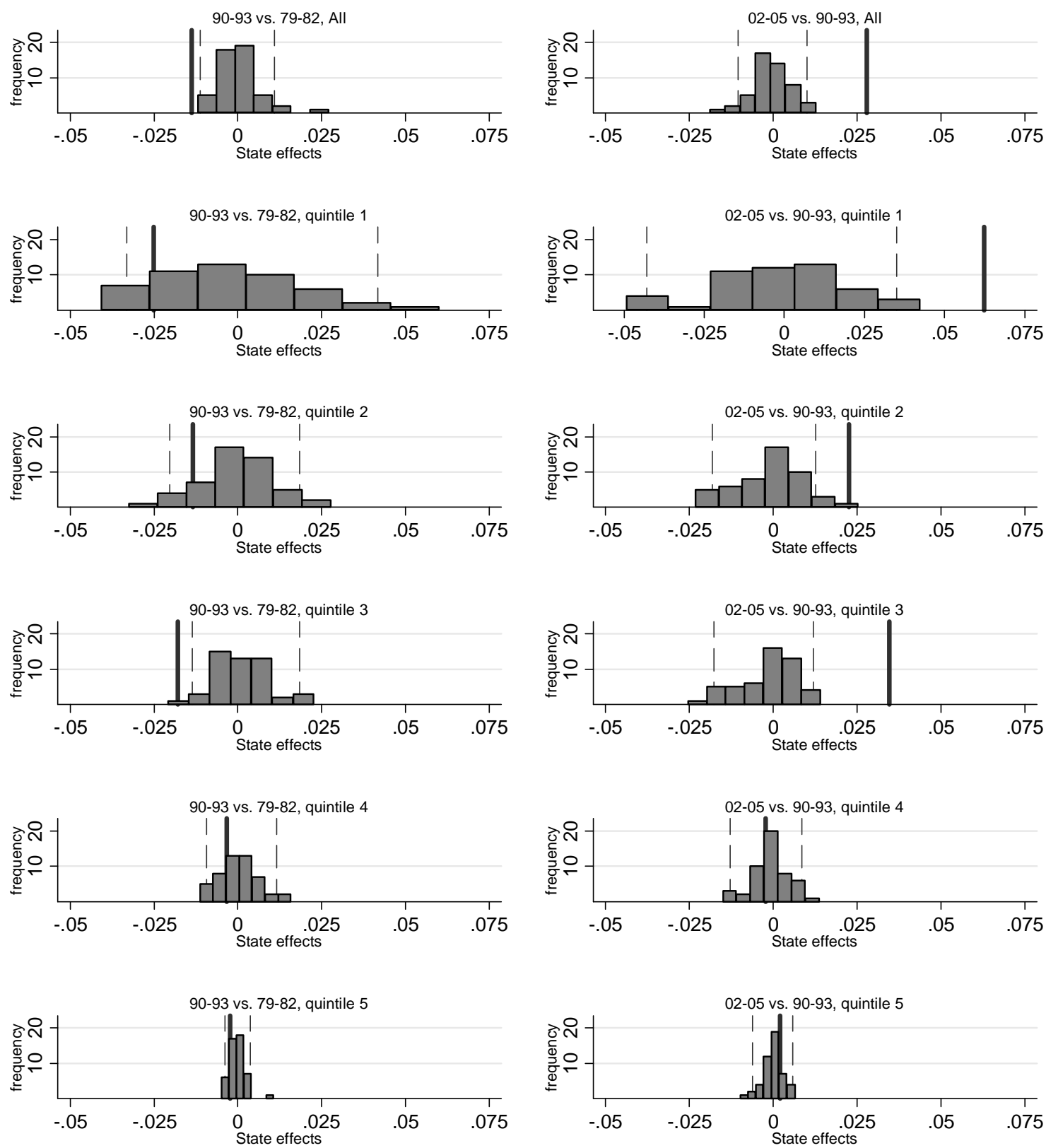

Note: Estimated using CPS MORG data, private sector workers age 18-64. The dashed lines are the 5th and 95th percentile values (other than Hawaii), the solid line is the Hawaii value. Logit models; covariates include the complete set of demographic/state and job controls (see Table 1). Effects estimated as treatment on the treated, converted to percentages (see text). Quintiles formed using fitted $\operatorname{Pr}(\mathrm{ESI})$, structure estimated for U.S. ex. Hawaii (see text). 
Figure B6: State Effects, Low Hours (by quintile) GOVERNMENT EMPLOYEES

Difference estimates (2002-05 minus 1979-82)
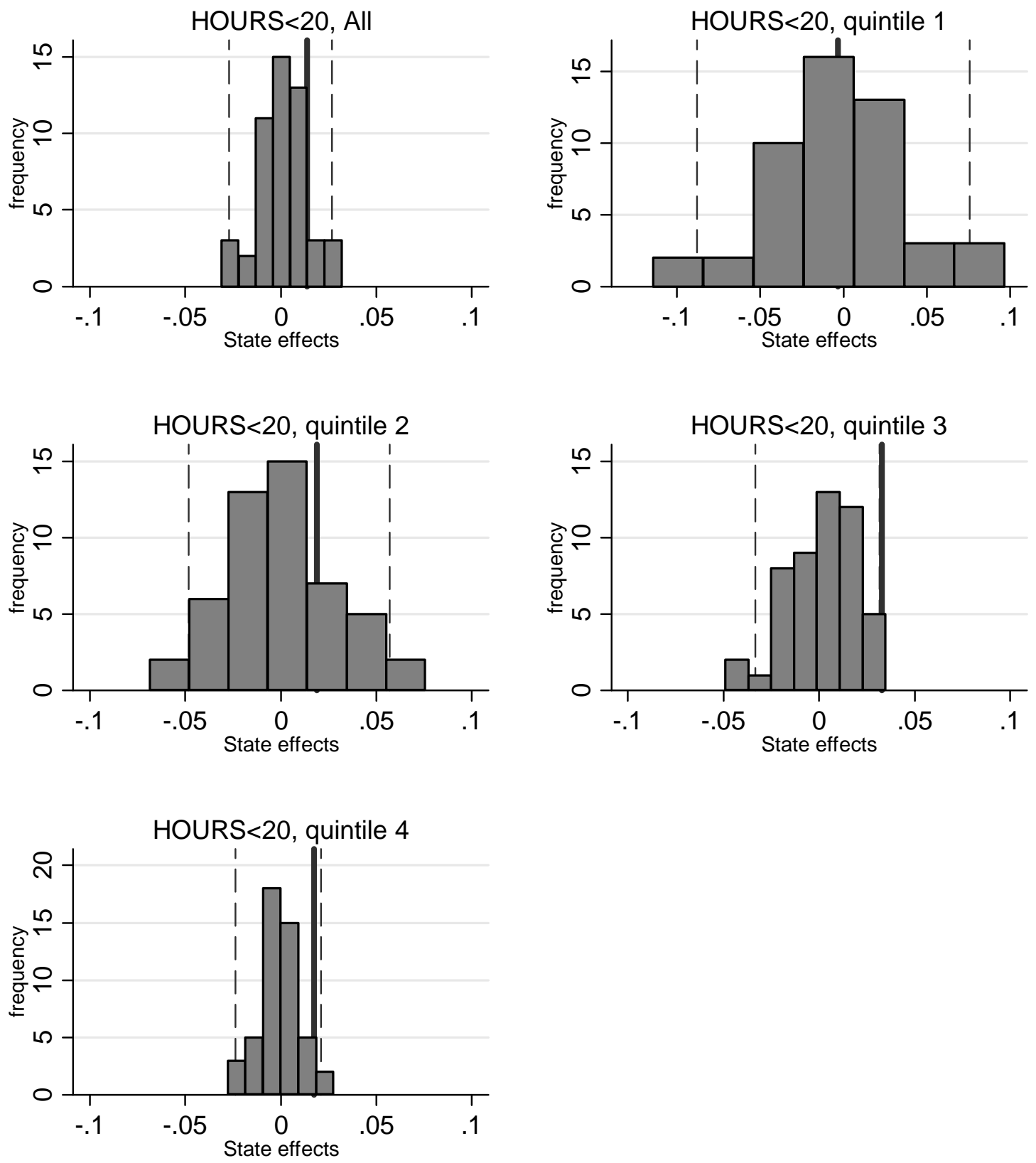

Note: Estimated using CPS MORG data, individuals age 18-64 (government employees only). The dashed lines are the 5th and 95th percentile values (other than Hawaii), the solid line is the Hawaii value. Logit models; effects are treatment on the treated, converted to percentages (see text). Full controls used (see Table 1), except industry and occupation. Quintiles formed using March CPS, fitted $\operatorname{Pr}(E S I)$ (government employees ony), structure estimated for U.S. ex. Hawaii (see text). Due to lack of variation, the Hawaii effect cannot be estimated for quintile 5 (hours<20); also, quintile 4 is based on 49 states other than Hawaii (rather than 50). 
Appendix C: Complete Regression Results (selected equations, 2002-05 sample)

\begin{tabular}{|c|c|c|c|c|}
\hline \multirow[b]{2}{*}{ VARIABLES } & (1) & (2) & (3) & (4) \\
\hline & $\begin{array}{c}\text { ESI Coverage } \\
\text { (logit), 2002-05 } \\
\text { (Table 1, Panel B) }\end{array}$ & $\begin{array}{l}\text { Log(wage), } \\
2002-05 \text { (used } \\
\text { for Table 2, } \\
\text { Panel A) }\end{array}$ & $\begin{array}{l}\text { Low Hours (logit), } \\
\text { 2002-05 (used for } \\
\text { Table 2, Panel B) }\end{array}$ & $\begin{array}{l}\text { Employed (logit), } \\
\text { 2002-05 (used for } \\
\text { Table 2, Panel C) }\end{array}$ \\
\hline \multirow[t]{2}{*}{ Hawaii dummy } & $0.914 * *$ & -0.00738 & -0.0851 & $0.405 * *$ \\
\hline & $(0.0781)$ & $(0.0209)$ & $(0.0714)$ & $(0.0488)$ \\
\hline \multirow[t]{2}{*}{$\operatorname{Ln}($ state min. wage $)$} & -0.0908 & $0.258 * *$ & 0.237 & -0.0442 \\
\hline & $(0.160)$ & $(0.0612)$ & $(0.190)$ & $(0.166)$ \\
\hline \multirow[t]{2}{*}{ Change in $\ln ($ state GDP $)$} & 0.0750 & 0.0749 & $-2.538 *$ & 0.524 \\
\hline & $(1.087)$ & $(0.272)$ & $(1.177)$ & $(0.467)$ \\
\hline \multirow[t]{2}{*}{ State union density (nonfarm) } & 0.000770 & $0.00597 * *$ & $0.0125^{* *}$ & $-0.00733 *$ \\
\hline & $(0.00387)$ & $(0.00136)$ & $(0.00393)$ & $(0.00365)$ \\
\hline \multirow[t]{2}{*}{ Age } & $2.411 * *$ & $0.0397 * *$ & $-2.879 * *$ & $1.436^{* *}$ \\
\hline & $(0.114)$ & $(0.0139)$ & $(0.212)$ & $(0.0603)$ \\
\hline \multirow[t]{2}{*}{$\mathrm{Age}^{2} / 10$} & $-0.836^{* *}$ & 0.000706 & $1.042 * *$ & $-0.512 * *$ \\
\hline & $(0.0440)$ & $(0.00566)$ & $(0.0864)$ & $(0.0227)$ \\
\hline \multirow[t]{2}{*}{$\mathrm{Age}^{3} / 1000$} & $1.266^{* *}$ & -0.0132 & $-1.662 * *$ & $0.810^{* *}$ \\
\hline & $(0.0727)$ & $(0.00984)$ & $(0.147)$ & $(0.0368)$ \\
\hline \multirow[t]{2}{*}{ Age $^{4} / 100,000$} & $-0.705 * *$ & 0.00991 & $0.993 * *$ & $-0.490 * *$ \\
\hline & $(0.0436)$ & $(0.00619)$ & $(0.0888)$ & $(0.0216)$ \\
\hline \multirow[t]{2}{*}{ HS degree } & $0.576^{* *}$ & $0.131 * *$ & $-0.418 * *$ & $0.734 * *$ \\
\hline & $(0.0190)$ & $(0.00950)$ & $(0.0370)$ & $(0.0265)$ \\
\hline \multirow[t]{2}{*}{ Some college } & $0.628 * *$ & $0.221 * *$ & $0.0798 *$ & $0.936 * *$ \\
\hline & $(0.0242)$ & $(0.0111)$ & $(0.0327)$ & $(0.0318)$ \\
\hline \multirow[t]{2}{*}{ College degree } & $0.813 * *$ & $0.404 * *$ & 0.0528 & $1.242 * *$ \\
\hline & $(0.0275)$ & $(0.0138)$ & $(0.0582)$ & $(0.0374)$ \\
\hline \multirow[t]{2}{*}{ Post-college degree } & $0.943 * *$ & $0.599 * *$ & -0.106 & $1.513 * *$ \\
\hline & $(0.0312)$ & $(0.0157)$ & $(0.0663)$ & $(0.0444)$ \\
\hline \multirow[t]{2}{*}{ Female } & $-5.577 * *$ & $-0.497 * *$ & 3.088 & $5.977 * *$ \\
\hline & $(1.228)$ & $(0.160)$ & (1.979) & $(0.505)$ \\
\hline \multirow[t]{2}{*}{ Female*Age } & $0.631 * *$ & $0.0465^{*}$ & -0.455 & $-0.583 * *$ \\
\hline & $(0.133)$ & $(0.0189)$ & $(0.233)$ & $(0.0593)$ \\
\hline \multirow[t]{2}{*}{ Female*(Age $\left.{ }^{2} / 10\right)$} & $-0.253 * *$ & $-0.0172 *$ & $0.230^{*}$ & $0.179 * *$ \\
\hline & $(0.0517)$ & $(0.00795)$ & $(0.0960)$ & $(0.0244)$ \\
\hline \multirow[t]{2}{*}{ Female*(Age $\left.{ }^{3} / 1000\right)$} & $0.421 * *$ & 0.0241 & $-0.436 * *$ & $-0.219 * *$ \\
\hline & $(0.0858)$ & $(0.0142)$ & $(0.165)$ & $(0.0422)$ \\
\hline \multirow[t]{2}{*}{ Female $*\left(\mathrm{Age}^{4} / 100,000\right)$} & $-0.248 * *$ & -0.0110 & $0.271^{* *}$ & $0.0939 * *$ \\
\hline & $(0.0515)$ & $(0.00908)$ & $(0.101)$ & $(0.0261)$ \\
\hline \multirow[t]{3}{*}{ Married } & $0.0935^{* *}$ & $0.130 * *$ & $-0.767 * *$ & $0.884 * *$ \\
\hline & $(0.0216)$ & $(0.00400)$ & $(0.0622)$ & $(0.0141)$ \\
\hline & \multicolumn{3}{|c|}{54} & (continued) \\
\hline
\end{tabular}


Appendix C (continued)

\begin{tabular}{|c|c|c|c|c|}
\hline VARIABLES & $\begin{array}{c}\text { ESI Coverage } \\
\text { (logit), 2002-05 } \\
\text { (Table 1, Panel B) }\end{array}$ & $\begin{array}{c}(2) \\
\text { Log(wage), } \\
\text { 2002-05 (used } \\
\text { for Table 2, } \\
\text { Panel A) } \\
\end{array}$ & $\begin{array}{l}\text { Low Hours (logit), } \\
\text { 2002-05 (used for } \\
\text { Table 2, Panel B) }\end{array}$ & $\begin{array}{l}\text { Employed (logit), } \\
\text { 2002-05 (used for } \\
\text { Table 2, Panel C) }\end{array}$ \\
\hline Married*female & $\begin{array}{l}-0.876^{* *} \\
(0.0345)\end{array}$ & $\begin{array}{l}-0.103 * * \\
(0.00410)\end{array}$ & $\begin{array}{c}1.459 * * \\
(0.0673)\end{array}$ & $\begin{array}{c}-1.245^{* *} \\
(0.0310)\end{array}$ \\
\hline Black & $\begin{array}{l}-0.0527^{*} \\
(0.0232)\end{array}$ & $\begin{array}{l}-0.105^{* *} \\
(0.0108)\end{array}$ & $\begin{array}{l}-0.595 * * \\
(0.0428)\end{array}$ & $\begin{array}{c}-0.427 * * \\
(0.0331)\end{array}$ \\
\hline Non-white/black & $\begin{array}{l}-0.178^{* *} \\
(0.0330)\end{array}$ & $\begin{array}{c}-0.0818^{* *} \\
(0.00798)\end{array}$ & $\begin{array}{l}-0.278^{* *} \\
(0.0438)\end{array}$ & $\begin{array}{l}-0.434 * * \\
(0.0505)\end{array}$ \\
\hline Hispanic & $\begin{array}{c}-0.294 * * \\
(0.0240)\end{array}$ & $\begin{array}{c}-0.154 * * \\
(0.0129)\end{array}$ & $\begin{array}{l}-0.703 * * \\
(0.0511)\end{array}$ & $\begin{array}{l}-0.0862^{*} \\
(0.0356)\end{array}$ \\
\hline MSA residence & $\begin{array}{c}0.116^{* *} \\
(0.0272)\end{array}$ & $\begin{array}{c}0.143 * * \\
(0.00945)\end{array}$ & $\begin{array}{c}-0.0609 \\
(0.0374)\end{array}$ & $\begin{array}{c}0.0105 \\
(0.0348)\end{array}$ \\
\hline Veteran & $\begin{array}{c}-0.0389 \\
(0.0270)\end{array}$ & $\begin{array}{l}-0.0115^{*} \\
(0.00503)\end{array}$ & $\begin{array}{c}-0.0465 \\
(0.0478)\end{array}$ & $\begin{array}{l}-0.168^{* *} \\
(0.0153)\end{array}$ \\
\hline Industries: Mining & $\begin{array}{l}1.516^{* *} \\
(0.120)\end{array}$ & $\begin{array}{c}0.459 * * \\
(0.0357)\end{array}$ & $\begin{array}{c}-1.580 * * \\
(0.299)\end{array}$ & -- \\
\hline Construction & $\begin{array}{c}0.156^{*} \\
(0.0740)\end{array}$ & $\begin{array}{c}0.282 * * \\
(0.0164)\end{array}$ & $\begin{array}{c}-0.568^{* *} \\
(0.120)\end{array}$ & -- \\
\hline Manufacturing (non-dur) & $\begin{array}{l}1.259^{* *} \\
(0.106)\end{array}$ & $\begin{array}{c}0.264 * * \\
(0.0160)\end{array}$ & $\begin{array}{c}-1.241 * * \\
(0.125)\end{array}$ & -- \\
\hline Manufacturing (durable) & $\begin{array}{c}1.267 * * \\
(0.0824)\end{array}$ & $\begin{array}{c}0.287 * * \\
(0.0159)\end{array}$ & $\begin{array}{c}-1.706^{* *} \\
(0.138)\end{array}$ & -- \\
\hline Trans/comm/public utilities & $\begin{array}{c}0.936^{* *} \\
(0.0843)\end{array}$ & $\begin{array}{c}0.281 * * \\
(0.0147)\end{array}$ & $\begin{array}{c}-0.582 * * \\
(0.120)\end{array}$ & -- \\
\hline Wholesale trade & $\begin{array}{c}0.994 * * \\
(0.0790)\end{array}$ & $\begin{array}{c}0.238^{* *} \\
(0.0142)\end{array}$ & $\begin{array}{c}-1.018^{* *} \\
(0.110)\end{array}$ & -- \\
\hline Retail trade & $\begin{array}{c}0.476^{* *} \\
(0.0756)\end{array}$ & $\begin{array}{c}0.0181 \\
(0.0140)\end{array}$ & $\begin{array}{l}-0.191 \\
(0.101)\end{array}$ & -- \\
\hline Finance/ins/real estate & $\begin{array}{c}0.837 * * \\
(0.0855)\end{array}$ & $\begin{array}{c}0.271 * * \\
(0.0154)\end{array}$ & $\begin{array}{c}-0.937 * * \\
(0.113)\end{array}$ & -- \\
\hline Business services & $\begin{array}{c}0.186^{*} \\
(0.0784)\end{array}$ & $\begin{array}{c}0.177 * * \\
(0.0157)\end{array}$ & $\begin{array}{c}-0.355^{* *} \\
(0.113)\end{array}$ & -- \\
\hline Personal services & $\begin{array}{c}-0.0983 \\
(0.105)\end{array}$ & $\begin{array}{c}0.0246 \\
(0.0173)\end{array}$ & $\begin{array}{r}-0.0549 \\
(0.102)\end{array}$ & -- \\
\hline Entertainment services & $\begin{array}{c}0.433 * * \\
(0.122)\end{array}$ & $\begin{array}{c}0.0656^{* *} \\
(0.0180)\end{array}$ & $\begin{array}{c}0.377 * * \\
(0.124)\end{array}$ & -- \\
\hline Professional services & $\begin{array}{c}0.583 * * \\
(0.0823)\end{array}$ & $\begin{array}{c}0.135^{* *} \\
(0.0148)\end{array}$ & $\begin{array}{l}-0.129 \\
(0.111)\end{array}$ & -- \\
\hline
\end{tabular}

(continued) 
Appendix C (continued)
(1)
(2)
(3)

(4)

$\log ($ wage),

ESI Coverage 2002-05 (used Low Hours (logit), Employed (logit), (logit), 2002-05 for Table 2, 2002-05 (used for 2002-05 (used for

VARIABLES (Table 1, Panel B) Panel A) Table 2, Panel B) Table 2, Panel C)

Occupations: Managerial $1.095^{* *}$

$0.396^{* *}$
$-0.849 * *$ (0.0780) (0.0155)

Professional $0.833 * *$ $0.366^{* *}$

0.141

(0.0764)

(0.0155)

(0.121)

Technical

$0.928^{* *}$

$0.319 * *$

$-0.0485$

(0.0788)

(0.0132)

(0.121)

Sales

$0.446^{* *}$

0.180 **

$0.255^{*}$

(0.0699)

(0.0148)

(0.109)

Administrative

$0.751 * *$

$0.0904^{* *}$

0.101

(0.0735)

(0.0135)

(0.111)

Service

$0.212 * *$

$-0.0102$

$0.585^{* *}$

(0.0747)

(0.0122)

(0.108)

Prod/craft/repair

0.640 **

0.189 **

$-0.776^{* *}$

(0.0785)

(0.0147)

(0.129)

Operators

$0.541 * *$

0.0364*

$-0.125$

(0.0759)

(0.0137)

(0.124)

Transportation/moving

$0.325^{* *}$

0.0374*

0.232

(0.0732)

(0.0140)

(0.128)

Handlers/cleaners

$0.173 *$

$-0.0241$

$0.352 * *$

(0.0822)

(0.0127)

(0.113)

Constant

$-26.70 * *$

$0.513^{* *}$

25.33**

$-13.82 * *$

(1.059)

(0.167)

(1.747)

(0.626)

Observations

302156

350191

513086

6984926

R-squared

$--$

0.464

$--$

--

Note: Omitted categories are education $<$ high school degree, white race, agriculture industry, and farming occupations. Standard errors (clustered by state) in parentheses.

$* * \mathrm{p}<0.01, * \mathrm{p}<0.05$ (based on conventional t-tests) 